NBER WORKING PAPER SERIES

\title{
DIGITAL DISPERSION: AN INDUSTRIAL AND GEOGRAPHIC CENSUS OF COMMERCIAL INTERNET USE
}

\author{
Chris Forman \\ Avi Goldfarb \\ Shane Greenstein \\ Working Paper 9287 \\ http://www.nber.org/papers/w9287
NATIONAL BUREAU OF ECONOMIC RESEARCH 1050 Massachusetts Avenue
Cambridge, MA 02138

October 2002

We thank Tim Bresnahan, Steve Klepper, Roger Noll, Scott Stern, and Manuel Trajtenberg for comments. We also thank Harte Hanks Market Intelligence for supplying data. We received funding from the Kellogg School of Management and the GM Strategy Center and seed funding from the National Science Foundation and Bureau of Economic Analysis. All opinions and errors are ours alone. The views expressed herein are those of the authors and not necessarily those of the National Bureau of Economic Research.

(C) 2002 by Chris Forman, Avi Goldfarb and Shane Greenstein. All rights reserved. Short sections of text, not to exceed two paragraphs, may be quoted without explicit permission provided that full credit, including (C) notice, is given to the source. 
Digital Dispersion: An Industrial and Geographic Census of Commercial Internet Use

Chris Forman, Avi Goldfarb and Shane Greenstein

NBER Working Paper No. 9287

October 2002

JEL No. L63, L86, O33

$\underline{\text { ABSTRACT }}$

Our study provides the first census of the dispersion of Internet technology to commercial establishments in the United States. We distinguish between participation, that is, use of the Internet because it is necessary for all business (e.g., email and browsing) and enhancement, that is, adoption of Internet technology to enhance computing processes for competitive advantage (e.g., electronic commerce).

Employing the Harte Hanks Market Intelligence Survey, we examine adoption of the Internet at 86,879 commercial establishments with 100 or more employees at the end of 2000 . Using routine statistical methods, we focus on answering questions about economy-wide outcomes: Which industries had the highest and lowest rates of participation and enhancement? Which cities, states and industries had a typical experience and which did not?

We arrive at three conclusions. First, participation and enhancement display contrasting patterns of dispersion. In a majority of industries participation has approached saturation levels, while enhancement occurs at lower rates and with dispersion reflecting long standing industrial differences in use of computing. Second, the creation and use of the Internet does not eliminate the importance of geography. Leading areas are widespread, whereas laggards are more common in smaller urban areas and some rural areas. However, the distribution of industries across geographic regions explains much of the difference in rates of adoption of the Internet in different areas. Third, commercial Internet use is quite dispersed, more so than previous studies show.

Chris Forman

Carnegie Mellon University

5000 Forbes Ave.

Pittsburgh, PA 15213

Shane Greenstein

Northwestern University

2001 Sheridan Road

Evanston, IL 60208

and NBER

greenstein@kellogg.northwestern.edu
Avi Goldfarb

University of Toronto

105 St George Street

Toronto, ON, Canada, M5S 3E6 


\section{Introduction}

Advances in frontier technology are only the first step in the creation of economic progress. The next step involves use by economic agents. Adoption by users typically needs time, invention and resources before economic welfare gains are realized. This principle applies with particular saliency to the Internet, a malleable technology whose form is not fixed across location. To create value, the Internet must be embedded in investments at firms and households that employ a suite of communication technologies, TCP/IP protocols and standards for networking between computers. Often organizational processes also must change.

The dispersion of Internet use to commercial users is a central concern for economic policy. As a general purpose technology (GPT) (Bresnahan and Trajtenberg 1995), the Internet will have a greater impact if and when it diffuses widely to commercial firms. This is particularly so because commercial firms do the vast majority of investment in Internet infrastructure, and at a scale of investment reaching tens of billions of dollars. Concerns about dispersion are difficult to address, however. Measuring dispersion requires a census of commercial Internet use, which, in turn, requires extensive data and an appropriate framework. This has not been done by any prior research. This study fills this gap.

We construct a census on adoption, the most common yardstick for measuring a new technology's use (Rogers, 1995). How widely dispersed is Internet technology across locations and industries? Which regions and industries adopt often and which do not? How does this measurement of dispersion compare with other ways of measuring the spread of the Internet?

Three themes shape our approach to answering these questions. First, our approach is consistent with standard ruminations about the strategic advantages affiliated with adoption of Internet technology. For example, some investments in Internet technology are regarded as "table

stakes"- they are required for companies to be a player in a market — whereas other investments are 
regarded as the basis of competitive advantage (Porter 2000). Second, our framework extends principles of "universal service" to Internet technology (Compaine, 2001, Noll et. al., 2001). Third, since there is no preset pattern for the adoption of GPTs, we seek to understand document differences in adoption between industries and locations.

We propose to analyze the dispersion of use of the Internet in two distinct layers. In one layer - hereafter termed participation — investment in and adoption of Internet technology enables participation in the Internet network. Participation is affiliated with basic communications, such as email use, browsing and passive document sharing. It also represents our measure of "tables stakes," namely, the basic Internet investment required to do business. In the second layer-hereafter termed enhancement - investment in and adoption of Internet technology enhances business processes. Enhancement uses Internet technologies to change existing internal operations or to implement new services. It represents our measure of investment aimed at competitive advantage.

Our analysis covers all medium and large commercial users, approximately two-thirds of the workforce. We use a private survey of 86,879 establishments with over 100 employees. The survey is updated to the end of 2000. Harte Hanks Market Intelligence, a commercial market research firm that tracks use of Internet technology in business, undertook the survey. We use the County Business Patterns data from the Census and routine statistical methods to generalize our results to the entire population of medium to large establishments in the United States.

We develop three major conclusions: First, we conclude participation and enhancement display contrasting patterns of adoption and dispersion. Overall, we find an average rate of adoption in excess of $88 \%$; participation is near saturation in a majority of industries. By any historical measure, such extensive adoption is quite remarkable for such a young technology. In contrast, though enhancement is widespread across industries and locations, the rate is much lower than that 
found for participation. Such investment occurs at approximately $12.6 \%$ of establishments. By the long-standing norms for different industries, this pattern of investment is not surprising.

The finding for participation suggests that Internet adoption costs are low and the benefits are high. The finding for enhancement suggests that Internet adoption costs are high and benefits more variable. We argue that both perceptions are correct, even though they appear to contradict each other on the surface. Each perception reflects the distinct economic costs and benefits from investment activities affiliated either participation or enhancement. More to the point, the productivity associated with investments in participation and enhancement are distinct, meriting separate analyses.

Second, we show that Internet technologies displayed geographic usage patterns common to other communication technology, however we argue different reasons from other authors. Specifically, there is evidence consistent with a mild geographic digital divide in both participation and enhancement. Although participation is high, the average establishment in a small metropolitan statistical area (MSA) or rural area is about $10 \%$ to $15 \%$ less likely to participate than one in the largest MSAs. Also, establishments in MSAs with over one million people are one and a half times as likely to use the Internet for enhancement than are establishments in MSAs with less than 250,000 people.

Why do some regions lead and others lag? We offer an explanation that differs sharply with the literature on digital divide. We conclude that the (pre-existing) distribution of industries across geographic locations explains much of the differences in rates in enhancement. This is not the entire explanation, but it is the most self-evident one. Moreover, because leadership in enhancement is quite dispersed across industries, it is also quite dispersed across locations. Hence, we question the prevailing opinion that the dispersion of the Internet sharply benefited a small number of regions. Consequently, we argue that regional growth policies have focused on correcting lack of participation or concentration of technologies in a few locations, but should additionally focus on understanding 
how regional growth policies can broaden the foothold that enhancement has across the majority of regions.

Third, existing studies fail to document the dispersion of use by commercial establishments. We establish this by comparing our data with other measures. We find that the geographic dispersion of commercial Internet use is positively related to the dispersion in household and farm use, as documented in previous research, but the relationship is not strong. Hence, we conclude that previous studies provide a misleading picture of dispersion. ${ }^{1}$

More broadly, we also conclude that existing surveys of commercial firms provide an incomplete picture of adoption and its dispersion. For example, the US Census has undertaken a large one-time survey of manufacturing plants. ${ }^{2}$ Yet, manufacturing only comprises a third of US commercial establishments. Our study discusses the sense in which manufacturing does and does not represent the experience in other industries. In addition, several private surveys have analyzed the productivity benefits of Internet technologies at commercial firms, analyzing factors other than dispersion. ${ }^{3}$ In contrast, our approach aims for unprecedented geographic or industrial breadth, but doing so requires focusing on only for a few narrowly defined questions.

\section{Background}

Our framework builds on microstudies of Internet investment in commercial establishments and organizations. ${ }^{4}$ It is motivated by the user-oriented emphasis in the literature on GPTs .

\footnotetext{
${ }^{1}$ To be sure, there has been much progress. For information about PC use, see e.g., National Telecommunications Information Administration (2001), Census (2001), and Goolsbee amd Klenow (1999); and for the beginnings in measuring electronic commerce see, e.g., Fraumeni(2001), Landefeld and Fraumeni (2001), Mesenbourg (2001), or Whinston et al. (2001). We discuss this further below.

${ }^{2}$ See Atrostic, Gates, and Jarmin (2000), Mesenbourg (2001), and Atrostic and Gates (2001), as well as the Census (2002).

3 Also, the samples are often too small to study dispersion. See Varian et al. (2001), Whinston et al. (2001), Forman (2002), and Kraemer, Dedrick and Dunkle (2002).

${ }^{4}$ See e.g., Forman (2002), Jones, Kato and Pliskin (2002), Gertner and Stillman (2001), Carlton and Chevalier (2001), Tan and Teo (1998).

${ }^{5}$ See e.g., Bresnahan and Trajtenberg (1995), Bresnahan and Greenstein (2001), Helpman (1998).
} 


\subsection{General Purpose Technologies and the Commercialization of the Internet}

The diffusion of the Internet can be viewed in the context of observations about technological convergence (Ames and Rosenberg 1984), which is the increasing use of a small number of technological functions for many different purposes. Bresnahan and Trajtenberg (1995) develop this further in their discussion of GPTs, which they define as capabilities whose adaptation raises the marginal returns to inventive activity in a wide variety of circumstances. GPTs involve high fixed costs in invention and low marginal costs in reproduction. A GPT is adapted for any new use, and this adaptation takes time, additional expense and further invention. Following the literature, we label these as co-invention expenses. Studies have found that co-invention influences computing and Internet technology investments by business users (Bresnahan and Greenstein 1997, Forman 2002).

Almost by definition, GPTs have a big impact if and when they diffuse widely, that is, if they raise the marginal productivity of a disparate set of activities in the economy. As a practical matter, "disparate" means a great number of applications and industries, performed in a great number of locations. What stands in the way of achieving wide and disparate diffusion? Barriers arise as a result of users facing different economic circumstances, such as differences in local output market conditions, quality of local infrastructure, labor market talent levels, quality of firm assets or competitive conditions in output markets. Simply put, these barriers are different co-invention expenses.

There is no preset pattern for the dispersion of GPTs. They can diffuse in layers or waves (e.g., Lipsey, Becker and Carlaw 1998). Below we argue that analysis of the dispersion of the Internet to commercial business requires analysis of distinct layers. We hypothesize that the co-invention costs of certain types of Internet investment were low, whereas other bottlenecks persistently produced high co-invention costs. When costs for some activities were low, adoption of these aspects of Internet technology became required to be in business. When the costs were higher and the benefits 
variable for other aspects, firms were more circumspect, investing only when it provided competitive advantage.

Consequently, we ignore differences across applications and intensities of use within an establishment. We focus on two layers that vary across location and industry. We label these layers as participation and enhancement.

The first layer, participation, is a key policy variable. As noted, it represents the basic requirements for being at the table for medium and large businesses. By 2000, participation was regarded as a routine matter. ${ }^{6}$ Its emphasis also arises in many studies of ubiquitous communications networks. A ubiquitous network is one in which every potential participant is, in fact, an actual participant. Concerns about ubiquity emerge in policy debates about applying principles of "universal service" to new technologies (Cherry, Hammond and Wildman 1999, Compaine 2001, Noll et al, 2001). For our purposes, we recognize that many different policies for ubiquity target geographic variance in adoption (e.g., reducing urban/rural differences).

The second layer, enhancement, is another key policy variable because its use is linked to the productive advance of firms and the economic growth of the regions in which these firms reside. It usually arrives as part of other intermediate goods, such as software, computing or networking equipment. Implementation of enhancement was anything but routine. Enhancement included technical challenges beyond the Internet's core technologies, such as security, privacy, and dynamic communication between browsers and servers. Organizational procedures usually also changed. ${ }^{7}$ Benefits accrue to the business organization employing enhancement through the addition of competitive advantage, but the co-invention costs and delays vary widely.

\footnotetext{
${ }^{6}$ Examples of participation include browsing and posting text-based web pages, advertising on the World Wide Web (WWW), WWW browsing, and a basic intranet.
} 


\subsection{A framework for measuring regional and industrial dispersion}

Participation represents a measure of "table stakes," while enhancement represents a measure of investment for competitive advantage. ${ }^{8}$ Both layers of activity are important for economic advance, but each has distinct effects on regional and industrial growth. We do not necessarily presume that the two are closely related, but intend to measure the correlation between them.

We will measure the dispersion of Internet technology across locations and industries. Since there is no single way to measure dispersion, we will modify our analysis to the data available. Our first research strategy involves identifying leaders and laggards, and comparing their features. Given that this study is the first to examine such data, our primary goal is to document and rank. Because we are interested in measuring the dispersion of Internet use across industry and location rather than its evolution across time, an analysis of the cross-section data is sufficient for our purposes.

\section{Data and Method}

The data we use for this study come from the Harte Hanks Market Intelligence CI Technology database (hereafter CI database). The CI database contains establishment-level data on (1) establishment characteristics, such as number of employees, industry and location; (2) use of technology hardware and software, such as computers, networking equipment, printers and other office equipment; and (3) use of Internet applications and other networking services. Harte Hanks Market Intelligence (hereafter $\mathrm{HH}$ ) collects this information to resell as a tool for the marketing

\footnotetext{
${ }^{7}$ See for example, Malone, Yates, and Benjamin (1987), Hubbard (2000), Hitt and Brynjolfsson (1997), or Bresnahan, Brynjolfsson, and Hitt (2002).

${ }^{8}$ Careful readers will notice that this varies from the definitions employed by Porter (2000). This is due to a difference in research goals. Throughout his article, Porter discusses the determinants of, and shifting boundaries between, investments that provided table stakes and those that complement a firm's strategy and enhance competitive advantage. He argues that these levels vary by industry and differ from firm to firm. This is the proper variance to emphasize when advising managers about their firm's strategic investment. However, when measuring this variance for purposes of formulating policy advice it is useful to shift focus. Our measurement goals require both a standardized definition (of something of interest for policy, but consistent with the spirit of strategy research) and a consistent application across industries and locations.
} 
divisions at technology companies. Interview teams survey establishments throughout the calendar year; our sample contains the most current information as of December $2000 .^{9}$

HH tracks over 300,000 establishments in the United States. Since we focus on commercial Internet use, we exclude government establishments, military establishments and nonprofit establishments, mostly in higher education. ${ }^{10}$ Our sample contains all commercial establishments from the CI database that contain over 100 employees, 115,671 establishments in all; ${ }^{11}$ and $\mathrm{HH}$ provides one observation per establishment. We will use 86,879 of the observations with complete data generated between June 1998 and December 2000. We adopt a strategy of utilizing as many observations as possible, because we need many observations for thinly populated areas. ${ }^{12}$ This necessitates routine adjustments of the data for the timing and type of the survey given by HH. See the appendix.

\subsection{Data Description and Sample Construction}

In Table 1, we show a few features of our final sample. We sample corporate America well. The largest establishment in our sample has 56,000 employees. ${ }^{13}$ Forty-five percent of establishments are part of a multi-establishment firm. Nine hundred twenty-one of the Fortune 1000 are represented. However, we also have broad representation among smaller firms. The median establishment in our sample has 174 employees.

\footnotetext{
${ }^{9}$ Using rotating teams of interviewers, $\mathrm{HH}$ collects data for the CI database. While $\mathrm{HH}$ selects some establishments for a detailed interview on technology usage, others receive a shorter interview that highlights the most important uses of IT.

${ }^{10}$ Noncommercial establishments have distinct patterns of Internet use from commercial establishments. First, participation is a given at virtually every educational establishment in the US. Second, military establishments often use a technically separate network from that used by commercial establishments. Third, the impact of the use by these establishments, while important for the provision of many public goods, is distinct from that by commercial firms. ${ }^{11}$ Previous studies (Charles, Ives, and Leduc 2002; Census 2002) have shown that Internet participation varies with business size, and that very small establishments rarely make Internet investments for enhancement. Thus, our sampling methodology enables us to track the relevant margin in investments for enhancement, while our participation estimates may overstate participation relative to the population of all business establishments.

${ }^{12}$ If we were only interested in the features of the most populated regions of the country, then we could easily rely solely on the most recent data from the latter half of 2000 , about $40 \%$ of the data. However, using only this data would result in very small number of observations for most regions with under one million in population.

${ }^{13}$ This is the Walt Disney World Resort.
} 
Establishments vary in their use of Internet technology. The number of PCs per employee varies from 0 to $26.92 .{ }^{14}$ The average firm has 0.37 PCs per employee, and the standard deviation is large (0.53). Fifty-seven percent of establishments have a LAN, and 39\% have a server, mainframe or some other kind of non-PC computing hardware. In all, we sample a wide range of establishments.

In Table 2 our final sample is compared to the County Business Patterns data from the 1999

Census. The first row shows that our sample contains slightly less than half of all establishments with over 100 employees in the United States. While this is only $1.3 \%$ of all establishments, our data represents roughly one-third of all employment. The table shows that in terms of company size, region, industry and urban versus rural location the numbers are generally close. We slightly underrepresent MSAs (a proxy for urban counties) and Consolidated Metropolitan Statistical Areas, or CMSAs, (a proxy for large cities). Most industries are also represented in proportion to their actual distribution. The regional representation is close, with a slight under-sample of the Northeast and over-sample of the Mid-west. Our sample also includes a disproportionate number of (1) companies in rural areas and (2) large establishments (over 500 employees).

We compared the number of firms in our database to the number of firms in the Census. We calculated the total number of firms with more than 50 employees in the Census Bureau's 1999 County Business Patterns data and the number of firms in our database for each two-digit NAICS code in each location. ${ }^{15}$ We then calculated the total number in each location. This provides the basis for our weighting. The weight for a given NAICS in a given location is $\frac{\text { Total \# of census establishments in location }- \text { NAICS }}{\text { Total \# of census establishments in location }} \cdot \frac{\text { Total \# of establishments in our data in location }}{\text { Total \# of establishments in our data in location }- \text { NAICS }}$

\footnotetext{
${ }^{14}$ For example, the Allen Memorial nursing home in Mobile, AL has no PCs. A Worcester research center for the University of Massachusetts has 26.92 PCs per employee.

${ }^{15}$ We used 50 employees because many of our HH employment data comes later than 1999. Consequently, firms may have grown. Using 50 employees instead of 100 gives a comprehensive measure of the number of medium and large firms without the number of firms in our data ever being larger than the number in the census. We used two-digit NAICS instead of three digit NAICS for sample size reasons.
} 
In other words, the weights are the proportion of establishments in a location that are a given NAICS code, divided by the proportion of times it is in our database. This means that if our data undersamples a given two-digit NAICS at a location, then each observation in that NAICS-location is given more importance. The weights for industry are calculated similarly, but instead of each location being split into NAICS, each NAICS is split by state. ${ }^{16}$

Using two survey forms, HH surveyed establishments at different times. To adjust for differences in survey time and type, we econometrically estimate the relationship between an establishment's decision to participate or enhance as a function of its industry, location, timing of survey and form of survey. We then calculate predicted probabilities of adoption for each establishment as if it were surveyed in the second half of 2000 and were given the long survey. Once we weight by the true frequency of establishments in the population, we have information about establishments related to two-thirds of the US workforce. The more observations we have for a given region or industry the more statistical confidence we have in the estimate. See the appendix for further detail.

\subsection{Definitions of behavior}

Identifying participation was simple compared to identifying enhancement. We identify participation as behavior in which an establishment has basic Internet access or has made any type of frontier investment. In contrast, for enhancement, an establishment must have made the type of investment commonly described in books on electronic commerce. We identify enhancement from substantial investments in electronic commerce or "e-business" applications. We look for

\footnotetext{
${ }^{16}$ We also adjusted our data because of the establishment definition: HH's definition of an establishment does not always match the Census. In particular, what HH lists as two different establishments may only be one establishment under the Census definition. Where this occurred, we aligned the HH data with the definition listed in the Census. If the same firm was observed to operate in the same five-digit zip code with the same six-digit NAICS code, it is likely that the Census would consider it one establishment. There were 2440 establishments in our data that fit the above criteria. If two establishments were to be combined, then the weights were multiplied by one-half. Similarly, if there were $n$ establishments, the weights would be multiplied by $1 / n$. The number of firms in each location would also take these changes into account.
} 
commitment to two or more of the following projects: Internet-based enterprise resource planning or TCP/IP-based applications in customer service, education, extranet, publications, purchasing or technical support. Again, see the appendix.

In Table 3 we show the results of these definitions. Participation by establishments within the sample is at $80.7 \%$. The sample under-represents adopters, and our estimate of economy-wide distribution (using the true distribution of establishments from the Census) is $88.6 \%$. We list the same number for those engaging in enhancement. It is $11.2 \%$ in our sample (see Unweighted Average in Table 3) and $12.6 \%$ in the true distribution (see Weighted Average in Table 3). We also can estimate the rate of adoption by "experimenters," that is, those establishments with some indication of use, but not much. As one would expect for a technology still in the midst of diffusion, the proportion for experimenters (combined with enhancement) is considerably higher than for enhancement alone, reaching $18.1 \%$ for the unweighted average and $23.2 \%$ for the weighted average. We have explored this latter definition and found that it tracks the enhancement definition we use below, so it provides no additional insight about the dispersion of use. We do not analyze it further.

\section{Leading industries}

In Tables $4 \mathrm{a}$ and $4 \mathrm{~b}$ we list the estimates for participation and enhancement organized by twodigit NAICS industry; we list industries in the order of highest to lowest adoption rates. We first show the results for all two-digit NAICS industries in the left half columns, and then break them into their three-digit NAICS industries in the right half columns. We identify leading and laggard industries. We also list the standard errors and number of observations.

\subsection{Participation}

Our first finding is quite apparent in Table $4 \mathrm{a}$ - participation is high in every industry, reaching over $92 \%$-- near saturation -- in a majority of them. Of course, this is not a surprise after 
Table 3 , since the average rate of participation was $88 \%$. The striking feature in Table $4 \mathrm{a}$ is the skew of these results. Establishments in all but four two-digit NAICS industries are at $90 \%$ or higher. With rare exception, the Internet reaches almost everywhere. ${ }^{17}$ Participation clearly represents a low cost "table stakes".

We conclude that participation is virtually ubiquitous in all establishments excepting - at worst $-\mathrm{a}$ few industries. This dispersion is consistent with the popular perception that (1) adoption costs were low, (2) the Internet was available almost everywhere, (3) virtually any business experienced some benefit from adoption, (4) this diffusion saturated potential adopters sometime before the decline in Internet technology spending in 2001 and (5) the Internet became a necessity for US business by the end of the millennium.

This is remarkable for a technology that is less than a decade old. To our knowledge, no major historical technology diffused this fast to such a disparate set of using industries right after introduction -- not electricity, telephony, the steam engine, or the automobile (Helpman 1998, Rogers 1995). ${ }^{18}$

\subsection{Enhancement}

In Table $4 \mathrm{~b}$, we provide the estimates for adoption of enhancement. The lead adopters exceed adoption rates of $25 \%$. These are NAICS 55, management of companies and enterprises (27.9\%), and NAICS 51, media, telecommunications and data processing (26.8\%). These two industries are not statistically different from each other, but they are statistically higher than all other NAICS 2

\footnotetext{
${ }^{17}$ The two major low outliers are the two components of retail trade, each at $80 \%$ adoption rates. Looking more closely at the NAICS three-digit industries in retail trade, we see there are a few outliers. These are (more narrowly) NAICS 452, general merchandising stores (69\%); NAICS 447, gasoline stations (75\%); NAICS 444, building materials and garden equipment and supply dealers (73.7\%); and NAICS 445, food and beverage stores (72.1\%), all of which contribute many observations to their respective NAICS two-digit category. NAICS 452 has some apparent nonresponse bias, so we believe these estimates are a lower bound. That said, nonresponse bias cannot fully explain why retailing is lower than other industries. For example, if all of Walmart's establishments answered in the affirmative to participating in the Internet, then the estimate for general merchandising would increase from $36 \%$ to $60 \%$.

${ }^{18}$ Speed is usually associated with an incremental technical advance aimed at a narrow set of adopters, such as the replacement of iron by steel rails, of steam by diesel engines, of black and white by color broadcasting, and so on. Even so, these canonical innovations did not diffuse to all potential adopters in less than a decade, as observed here.
} 
industries. These first two lead user industries are remarkably different. NAICS 55 represents the financial side of the Internet revolution. It includes corporate headquarters for multidivisional firms, securities firms and financial holding companies. NAICS 51 includes publishing firms, thus representing the change the Internet brings to media. It also includes information and data processing services (NAICS 514), an industry that includes firms like America Online and other Internet access providers. This variety at the top is not a surprise, as the business press has largely described the wide impact of this technology's diffusion. The Internet has been used in a variety of industries to create competitive advantage. However, it confirms how varied was the impact of the diffusion of Internet technology - a theme that we will repeat as we look further down the table.

The second tier of lead users again includes a wide mix from two-digit industries, such as finance and insurance, professional and scientific services, utilities, and wholesale trade. These latter two industries include heavy users of sophisticated applications combining database software with communication technologies. The third tier of enhancement adopters includes NAICS 32 and 33, which together cover over $80 \%$ of manufacturing. Within this group a few notable lead industries at the NAICS three-digit level are NAICS 334, computer and electronic manufacturing (23.5\%), NAICS 323, printing and related support activities (18.\%), and NAICS 211, oil and gas extraction (18.4\%). These are all long-time lead users in computing, but for very different reasons.

Low adopters (under 6\% adoption) at the NAICS three-digit level do not surprise us. These include transit and ground passenger transportation (NAICS 485, 4.7\%), food services and drinking places (NAICS 722, 5.6\%), social assistance (NAICS 624, 5.9\%), and amusement (NAICS 731).

\subsection{Comparison with others' findings}

We compared our findings against two other recent studies of Internet technology use and a summary of historical adoption. First, we compared our estimates with Census estimates for 1999 on the use of networking by manufacturing plants, as reported in Atrostic and Gates (2001). This data 
was compiled from 40,000 surveys of large and small plants. The large plants in their samples and ours largely overlap; but their sample contains plants with fewer than 100 employees and ours does not. Atrostic and Gates focus only on three measures of business process adoption in manufacturing: percentage of firms that use networks; percentage of employees that use networks; and percentage of plants with fully integrated enterprise software. However, we find that our data and theirs give a similar picture. Despite differences in sampling frame, our estimate of enhancement is close to theirs for adoption of networking and enterprise software (correlation coefficients for NAICS three-digit manufacturing industries is 0.40 and 0.48 ). Not surprisingly, their question about employee use of networking is less correlated with our estimate (0.18). We conclude that our measure partially overlaps with the Census results because we both measure similar phenomena. But we also conclude that our measure captures something distinct beyond just networking.

Second, we also compared our estimates with Bureau of Economic Analysis (BEA) data on communications and capital service flows per industry, as used by Stiroh (2002b). Although the BEA data uses Standard Industrial Classification (SIC) codes rather than NAICS codes, we matched fortythree industry categories. We found that investment in computers and communication is positively but weakly correlated with both participation $(\mathrm{rho}=0.121)$ and enhancement $(\mathrm{rho}=0.080)$. A weak result is not surprising since the two series use different units, which are not very comparable. Our estimates measure enhancement adoption per establishment in an industry, whereas the BEA numbers measure dollars for all firms in an industry. The Spearman Rank Coefficient eliminates this mismatch of unit scale and, accordingly, is much higher and statistically significant for both participation and enhancement (respectively 0.37 and 0.34 ). In other words, Internet technology-intensive industries 
tend to be those where a high fraction of establishments are adopting the Internet for enhancement. In addition, that Internet technology investment goes for more than just Internet business processes. ${ }^{19}$ Finally, we compared our list of lead industries with similar lists from more than two decades ago. The list of "leading" computer users in the late 1970s to early 1980s remains on our list of medium to large adopters. Cortada (1996) lists lead industries as banking and finance, utilities, electronic equipment, insurance, motor vehicles, petroleum refining, petroleum pipeline transport, printing and publishing, pulp and paper, railroads, steel, telephone communications and tires. However, wholesale trade is a low user, so too is water transportation. How did these industries change status in two decades? In short, these industries include many establishments that use communications to enhance logistical operations, which was difficult to do electronically more than two decades ago. Aside from this exception, his list of laggards also corresponds with our list. Cortada does not list broadcasting at all, nor retailing, so we cannot make a comparison there. ${ }^{20} \mathrm{We}$ conclude that the leading and lagging users of the new economy look a lot like leading and lagging users in the old computing economy. This also opens questions about why the costs and benefits of innovative information technology have not changed much in decades.

\subsection{Industry investment in broader perspective.}

Our findings lead us to four areas of inquiry. First, our findings warn against inferring too much from the experience in manufacturing. The Census collected a lot of detail about manufacturing, but its establishments are medium to high adopters, neither leaders nor laggards.

\footnotetext{
${ }^{19} \mathrm{We}$ also experimented with separating communications and computing, following Stiroh (2002a, 2002b). The results are qualitatively similar. The rank correlation between communications enhancement is mildly lower. There is a high rank correlation between computing and participation that is mildly higher.

${ }^{20}$ Our estimates cannot be directly compared against another historical study of lead users, Bresnahan and Greenstein (1997). That study examines the diffusion of client-server technology to former mainframe users in the early 1990s. First, the Bresnahan and Greenstein study concerns mainframe users, and it over-samples some industries relative to this population. Second, the results highlight the role of co-invention costs, which overwhelmed the benefits of adjusting at many traditional information-intensive users. This prevented or slowed down adoption of new technology on a large scale in many industries, except those with scientific or engineering users. In contrast, after several years of the diffusion of the Internet, the benefits were large enough to induce new investment activity in virtually every industry. See Forman (2002) for a discussion of co-invention costs in Internet technology when it first diffused.
} 
Establishments in other industries are outside this picture. Finance and media have many more lead adopters--as a fraction of total establishments within each sector--and possibly a very different set of applications.

Second, we find that Internet technology producers (as well as their distributors) are frequent adopters. This echoes a finding that information technology and electronics manufacturers are intensive users of computing and communications as inputs (e.g., Stiroh 2002a). However, there are two differences: Manufacturers and distributors of electronics both are lead adopters. Moreover, these establishments are far from being the only lead adopters. They are two among a crowd.

Third, the composition of this distribution has old as well as new information to investigate. There are the familiar lead industries from information service industries, scientific and technical industries, and finance, insurance and real estate. The flip side of the coin is similar: Most laggard industries (i.e., infrequent computing and computer adopters two decades ago) did not suddenly become Internet-intensive. The exceptions are informative about the nature of building competitive advantage using Internet technologies. The appearance of transportation and warehousing as lead industries shows that the Internet influenced establishments where logistical processes played a key role. At the same time, it raises a large open question about why there is such durability in the factors shaping the dispersion of innovation information technology across industry.

Fourth and finally, these estimates foreshadow our findings about the geographic distribution of enhancement. First, participation is almost at saturation, so the same will have to be true across most locations - simply for the sake of statistical consistency. It is also well known that some lead industries in enhancement, such as corporate headquarters and financial firms, disproportionately locate establishments in dense urban settings. That said, there are many industries from disparate settings that are close to these leaders. If the location of establishments from these industries does not overlap much (and they will not), then adoption will disperse widely across locations. 


\section{Distribution Across Metropolitan Areas}

In this section we present estimates of the dispersion of Internet technology to urban businesses. We identify features of urban leaders and laggards. We also develop our argument that the (preexisting) geographic distribution of industries is responsible for the Internet technology's geographic distribution.

Tables $5 \mathrm{a}$ and $5 \mathrm{~b}$ cover the largest economic areas in the United States. In them we list the estimates for both participation and enhancement, organized by MSAs with over one million people and listed by areas in the order of highest to lowest adoption rates. ${ }^{21}$

In Tables $6 \mathrm{a}, 6 \mathrm{~b}$ and $6 \mathrm{c}$ we summarize results for all MSAs by population. We list one row for MSAs with over one million in population (hereafter termed large MSAs), then MSAs between onequarter million and one million (hereafter termed medium MSAs), and then MSAs under one-quarter million (hereafter termed small MSAs). Finally, we show the estimates for the top ten areas for enhancement in Tables 7a, b and c, which cover all urban areas. As before, we also list the standard errors $^{22}$ and number of observations to show where we have statistical confidence in the estimates.

\subsection{Participation}

Table 5a shows that participation is high in major urban locations. Virtually all establishments in the major urban areas are participating; they have paid the "table stakes." We estimate that thirty-five of the forty-nine major metropolitan areas (CMSAs) are above 90\%. All but five are within a $95 \%$ confidence interval of $90 \%$. Big differences among metropolitan areas are

\footnotetext{
${ }^{21}$ When two or more MSAs are part of the same urban environment, the census combines them into CMSAs. For example the Dallas-Fort Worth CMSA contains both Dallas and Forth Worth. In Table 5 we present the CMSA results rather than the individual MSA results when an MSA is part of a CMSA. However, because we will be comparing data between metropolitan areas of different sizes, the only standard of measure we can use is the MSA, as opposed to the CMSA, which applies only to large areas. Thus, in our tables 6 and 7 we will be discussing rates of adoption in MSAs. This causes for a slight shift in the hierarchy of leaders and laggards. (See, for example, the minor changes in the top ten leaders of enhancement between Tables $5 \mathrm{~b}$ and $7 \mathrm{a}$.)

${ }^{22}$ These are again computed using the delta method. See the previous footnote on computation of standard errors.
} 
apparent only at the extreme. The bottom ten areas range from $89.1 \%$ in Pittsburgh to $84.6 \%$ in

Nashville. Although these are the lower adopting areas, they are not very low in absolute value.

From Table 6a we see that large MSAs are somewhat exceptional with their average participation of $90.4 \%$. Participation in medium MSAs averages $84.9 \%$. In small MSAs the participation rates are even lower, $75.5 \%$ on average. ${ }^{23}$

We examined participation across 320 MSAs in the country (unweighted by population size). ${ }^{24}$ The median MSA in the United States has participation at $84.3 \%$. The lower quartile is $76.4 \%$. Of the 80 MSAs in the lowest quartile, 69 have a population of under one-quarter million. In other words, very low participation in urban settings, when it arises, exists primarily in small MSAs.

\subsection{Enhancement}

In Table 5b we examine the use of enhancement at establishments in CMSAs with over one million people. We estimate that thirty-eight of the forty-nine areas are above $12.5 \%$. All but one are within a $95 \%$ confidence interval of $12.5 \%$. The top ten include a set of areas that partially overlaps with the list in Table 5a. It begins with the greater Denver area (with 18.3\%) at number one and the greater Portland area at number ten (with 15.1\%). In between are the greater San Francisco Bay Area, the greater Salt Lake City area, Minneapolis/St Paul, the greater Houston area, Atlanta, Oklahoma City, Dallas/Fort Worth, and San Antonio. Again, big differences with these leaders are only apparent at the extremes. The bottom ten areas range from $12.4 \%$ in Phoenix to $9.0 \%$ in Las Vegas. Even so, these low adopting areas are, once again, not very low relative to the average.

Overall, establishments in urban settings are more likely to adopt enhancement than those located outside major metropolitan areas. Table 6a shows the adoption of enhancement in MSAs of

\footnotetext{
${ }^{23}$ The last column of Table 6 partly hints at the explanation for these differences: The fraction of establishments from retailing is higher in smaller MSAs. Judging from the low adoption rate by some retail establishments, particularly WalMart, it seems likely that some may have responded negatively to adoption questions for strategic reasons. However, that alone cannot fully account for the difference. Even if we assume retail adoption is $100 \%$, it will explain at most $43.6 \%$ of the difference between large and medium MSAs and $17 \%$ of the difference between medium and small MSAs. There are still large differences by MSA size.
} 
different population size, highlighting again that large MSAs are somewhat exceptional.

Establishments in large MSAs have adoption rates of 14.7\%. In medium MSAs, it averages 11.2\%. In small MSAs the rates are even lower, $9.9 \%$ on average. The second and third columns of Table $6 \mathrm{~b}$ strongly hint at the explanation for these differences. Remember that in Table $4 \mathrm{~b}$ the upper quartile of two-digit NAICS industries with the highest enhancement adoption rates includes management of companies and enterprises (55), media, telecommunications and data processing (51), utilities (22), finance and insurance (52), profession, scientific and technical services (54) and wholesale trade (42). The fraction of the number of these establishments over the total number of establishments in an MSA is highest in large MSAs (27.5\%). That accounts for much of the difference between larger and smaller MSAs.

Table $6 \mathrm{c}$ provides a test of this proposition. It shows the results from a simple regression that predicts enhancement for an MSA, illustrating the effect of area size and industry presence. The coefficient shows that a ten percent drop in the percent of firms from leading industries (from e.g., 0.3 to 0.2 ) would lead to the $2 \%$ drop in the enhancement rate within an MSA. The importance of industry continues to come through even with the addition of MSA size effects, interaction terms and other measures of laggard industries. ${ }^{25}$ In sum, an area is advanced because its establishments happen to come from a leading industry. To be fair, the presence of leading industries is not the only factor, but it is an important one. It alone explains $20 \%$ of the variance in enhancement.

In Table 7 we further examine differences in enhancement rates across small, medium and large MSAs, listing the ten leading MSAs for enhancement according to MSA size. In addition we look at the percentage of leading enhancement industries within each MSA. This breakdown of information highlights the differences between large, medium and small MSAs. These tables

\footnotetext{
${ }^{24}$ Since these results are simple, we discuss them only in the text. They are not reported in any table.

${ }^{25}$ We tried a number of variations on the same type of regression, with similar qualitative results. Hence, we show the simplest result here.
} 
reinforce the results in Table 6, showing that MSAs with leading enhancement rates are not only the larger ones, but also the ones with the highest percentage of leading establishments. Moreover, they show that the difference in enhancement rates between MSA sizes are driven by differences in industry composition at the lower tail of the distribution. Table 7a shows the enhancement rates for the top ten and bottom ten large MSAs. The average of the fraction of leading establishments in the top ten large MSAs (29.6\%) exceeds the fraction (21.7\%) in the bottom ten large MSAs (note that the laggards are not shown in this table).

In Table $7 \mathrm{~b}$ and $7 \mathrm{c}$ we can see that the levels of adoption among the leaders of medium MSAs are very similar to those shown in Table 7a, but the standard errors are much larger due to smaller sample size. These standard errors make us cautious to emphasize any details about particular locations in these ranking, but we are able to make broad statements. As before, among medium and small MSAs the average fraction of leading industries in the top ten medium MSAs ( $24.4 \%$ and 16.4\%) exceeds the average fraction of leading industries in the ten laggard medium MSAs (16.3\% and $11.1 \%)$. However, while leading medium and small MSAs are just as likely to be as advanced as leading large MSAs, there are a many medium and small MSAs with fewer establishments in the top quartile of enhancement adoption. In other words, the difference in distributions arises entirely at the lower tail.

\subsection{Comparison with other findings.}

We compared our findings against the National Telecommunications Information Administration (NTIA) studies of Internet technology use in households for the same year. This study is one among many from NTIA about the digital divide. We took the same raw survey data from 2000, which appeared in summary form in the NTIA 2001 report, and aggregated it up to MSAs. We were able to compute household adoption rates for PCs and the Internet for 231 MSAs, a sample 
weighted toward large to medium MSAs. ${ }^{26}$ The correlations between these MSA averages for households and our estimates for commercial establishments in the same location are positive but weak. They range between 0.13 and 0.17 . The rank Spearman correlations are mildly higher, between 0.17 and 0.22 .

We conclude that the household use of the Internet or computers is mildly informative about the use of the Internet at commercial establishments, as one would expect if the education of the local labor force influenced both. However, we also conclude that the correlation is weak within most medium to large MSAs. This is consistent with the view that commercial establishments in urban areas train their workers or simply find mobile technically adept employees. Our findings also support the view that the factors necessary to foster participation and enhancement to Internet business processes did not depend on local household behavior because these factors were widespread throughout the urban areas of the United States.

Internet technology spread to commercial businesses in many areas of the United States. Unlike much previous literature ${ }^{27}$ we find no evidence that this technology is being dominated by a small set of users concentrated in a small region, whether it is in Silicon Valley, along Route 128 outside of Boston, or in any other major urban center. Participation was widespread by the end of 2000, though it tends to mildly favor establishments in heavily populated areas. The use of enhancement to gain competitive advantage spread widely but favored medium and large urban areas with a heavy mix of industries that were high adopter industries. The determinant of differences between MSAs of different size occurs at the bottom tail. Large MSAs have fewer laggards than medium and small MSAs. We conjecture that these laggard small and medium MSAs may suffer

\footnotetext{
${ }^{26}$ Disclosure rules prevent the cell size from becoming too small. Hence, this sample undersamples small MSAs. The smallest cell size for any MSA in this data is six observations, for the next smallest it is eight, for the next it is ten. ${ }^{27}$ See, e.g., Kolko (2002), Moss and Townsend (1997), Zooks (2000a, 2000b), Saxenian (1994), Castells (2002).
} 
from an inability to achieve scale economies in secondary markets for programmer, technical and other complementary services.

We will say more about the urban/rural divides below, but we speculate at this point that the difference in findings between our study and previous studies arises for four reasons: (1) We are observing medium to large commercial adopters, who have the highest propensity to invest in Internet technology; (2) We are observing their behavior late enough in the diffusion cycle to overwhelm geographic biases associated with very early experimentation (i.e., early experimentation tends to favor areas with a high proportion of technical and scientific users); (3) We are observing business use, which has quite distinct determinants compared with household and farm adoption of computing and internet technology; (4) We are observing use of technology, not production or design of new products, and the latter tends to receive much more attention in public discussion, but leaves a false impression about use.

\subsection{Urban dispersion in broader perspective}

We close by noting that the geographic distribution of establishments largely existed prior to the commercialization and diffusion of the Internet. This leads to three conclusions. First, the preexisting distribution of establishments from different industries shaped the diffusion of networking technology.

Second, this technology was adopted across many industries -- not all of which share similar geographic distributions. Hence, there are straightforward economic reasons why this use of this technology had a large dispersion over geographic space. It would have taken an implausibly fast and massive relocation of existing establishments and labor markets to concentrate this technology in a small number of places.

Third, concerns about the concentration of use (as emphasized in studies of the digital divide and early development of Internet infrastructure) are out of proportion with the technology's actual 
pattern of diffusion in business. To be sure, there are leader and laggard regions, but we hardly find it alarming, nor surprising, for an expensive business technology just past its early stages of development.

In this sense, we agree strongly with analysts who argue that geography plays a role in shaping the diffusion and impact of virtual communities. ${ }^{28}$ At the same time these findings make us skeptical that this technology's diffusion is headed toward geographically concentrated use. Too many regions have numerous establishments using the Internet for enhancement.

\section{Urban/rural divides across states}

Tables $8 \mathrm{a}$ and $8 \mathrm{~b}$ present adoption rates for participation and enhancement for rural and nonrural establishments across all the states in the United States except New Jersey and the District of Columbia. $^{29}$ This is also a useful framing for policy, since many policies for encouraging universal service within rural communities are determined by state regulators and legislatures.

\subsection{Participation and enhancement}

The estimates for participation in Table 8a are high in most rural establishments, as expected. One striking feature of the table is its spread. There are only five states where the rate of participation in rural areas is lower than $80 \%$, and eighteen below $87 \%$; however, this is still worse than in urban areas. There are two states with urban areas below $80 \%$ adoption (Vermont and Montana) and only six below $87 \%{ }^{30}$

The estimate for rural enhancement adoption in Table $8 \mathrm{~b}$ has a distinct distribution. The enhancement rates in the leading states are comparable with the leading metropolitan areas. The lead

\footnotetext{
${ }^{28}$ In addition to those already cited, see research on the geography of cyberspace. See, e.g., Cairncross (1997), Kitchin and Dodge (2001), Kotkin (2000), Kolko (2002), Castells (2002) chapter 8, Zooks (2000a, 2000b).

${ }^{29}$ New Jersey has only one rural establishment in our data and D.C. has none.

${ }^{30}$ Note, too, that the lower adoption rate for rural areas is a phenomenon common to many states, not just the states with high rural participation. Indeed, urban and rural participation in the same state are not especially related. Participation rates are positively correlated but small (at rho $=0.021$ ).
} 
state is Minnesota with a rate of $15.5 \%$. This is followed by Rhode Island, South Carolina, Louisiana, New York, Ohio, West Virginia, Wyoming, Utah and Alaska. In the leading rural states the rates in the urban and rural areas are comparable. However, the differences in the lower tail are large. Twenty-four states have rural enhancement rates below $10 \%$, while only three states have urban rates under $10 \%$.

We compare the rank ordering of $8 \mathrm{a}$ and $\mathrm{b}$. Five states are in the top ten of both tables. Generally, however, the ranking in both tables are only weakly correlated. The Spearman rank correlation coefficient is 0.296 , positive but not large. Again, this is further evidence that participation and enhancement are distinct.

\subsection{Comparison with other findings}

We compared our estimates with a previous survey of rural Internet technology development - the United States Department of Agriculture (USDA) estimates for computer and Internet use by US farmers, summarized at the state level. ${ }^{31}$ We also compared our estimates with the NTIA estimates for household adoption at the state level, which combine urban and rural households. The correlation between participation at rural commercial establishments and farm computer use is 0.41 , and between rural participation and farm Internet use it is 0.28 . The correlation between enhancement at rural commercial establishments and farm computer use is 0.18 , and between rural enhancement and farm Internet use it is 0.17 . These correlations are positive. Only the first one is large.

We conclude that the USDA survey is an incomplete assessment of nearby commercial Internet use. This should not come as a surprise. Our survey and theirs should be positively related, because the level of sophistication of the general population influences adoption at farm and nonfarm establishments. However, the motives for adoption differ between farming and nonfarming

\footnotetext{
${ }^{31}$ The USDA groups several states together, so we only can compare 30 states. We use the data released 30 , July 2001 , available at http://usda.mannlib.cornell.edu/reports/nassr/other/computer/.
} 
establishments. These results warn against inferring much about rural conditions from farm data alone.

As another important lesson in the economic geography of the Internet policies, Tables 9a and $\mathrm{b}$ include adoption rates for states. As indicated by many previous tables, this level of aggregation hides much variance at the MSA and rural levels. The open question is "How badly do you do if state data is the only thing available?" First, we look at participation. This distribution lacks much variance; no state is exceedingly higher than others. The highest state (Massachusetts at $92.4 \%$ ) is hardly higher than the median state (Arkansas at $89.4 \%$ ). Only six states are below $87 \%$. Next, we examine enhancement across states. Again, there is not much of a spread. The highest state (Colorado at $16.7 \%$ ) is not much higher than the median (Nebraska at 12.8\%), and the difference in point estimates are not statistically significant at a $95 \%$ confidence level. Only three states are less than $10 \%$ in their point estimates, and none are below $10 \%$ at traditional significance levels. In general, because urban and rural are not highly correlated, these state-level statistics mask the information in more detailed data. At the same time the rates for participation and enhancement positively correlated (at 0.40).

We also compared our estimates with the NTIA estimates of Internet household use at the state level. ${ }^{32}$ This differs from the comparison above because it is at a different level of aggregation (state instead of MSAs). The present comparison also includes households from thinly populated areas, which were dropped in the previous comparison due to privacy concerns. We find that participation is not correlated with estimates of household use of the Internet (at 0.05). At best, enhancement is correlated with household adoption of the Internet (at 0.37 ). The results follow the same reasoning as above. These are positive, reflecting differences in regional labor markets.

\footnotetext{
${ }^{32}$ See National Telecommunications Information Administrations, 2001.
} 
However, these are also small enough to suggest that the NTIA survey provides an incomplete picture of commercial Internet use without further detail.

\subsection{Urban/rural divides in broader perspective}

We conclude that enhancement needs to be understood at a fine geographic level, preferably with data relating adoption to MSA and establishments. When this is done, it is apparent that in terms of both participation and enhancement, there are distinct differences between the establishments found in the most populous urban centers and the least dense, even within the same state. We further conclude that concerns about digital divide in commercial establishments are justified, but only if properly qualified. Since participation was not costly, it is surprising and disturbing to find any establishment in any area with low participation. To be sure, if these disparities persist, then it is worrisome for business prospects in those locations since every other establishment in the United States takes this technology for granted. That said, the scope of the problem is limited: Laggard areas do not come from major urban areas.

The dispersion of enhancement provides a different set of insights. This distribution is much more skewed. Yet, such skew is not strong evidence of a digital divide. It is more understandable as an economic matter. First, skew could arise alone from thin technical labor markets in smaller MSAs and rural areas. This would drive up costs of operating facilities employing Internet technology. Because the investment is linked to competitive settings, multi-establishment organizations, if they had a choice, would implement new business processes in more hospitable settings in major urban areas.

Second, this reasoning also suggests that preexisting single-establishment organizations would hesitate to open their own complex Internet facilities until the costs are lower. Either case would lead to more use of enhancement in major urban areas. 
At the same time, we recognize that our findings raise a large open question. What role, if any, did location play in the adoption of the Internet once industry effects are taken into account? We cannot answer this question without close examination of micro-evidence about factors such as size of establishments, controlling for regional effects at a detailed level. This is a topic for further research.

\section{Conclusions}

Our study contains three major conclusions about the adoption of the Internet at commercial establishments. First, in a majority of industries the establishments participate in the Internet at near saturation levels, while the Internet is used for enhancement to create competitive advantage at much lower rates. Second, geography shapes the dispersion of Internet use. We find a geographic digital divide in commercial adoption of the Internet, where leading areas are widespread and laggards are more common among smaller urban areas. However, the distribution of industries across geographic space has much to do with the different rates of Internet adoption in different areas. Third, commercial Internet use is quite dispersed, more so than previous studies show. We highlight implications below.

\subsection{Layered dispersion}

We demonstrated the importance of distinguishing between different layers of Internet technology. Rapid diffusion in participation did not necessarily imply rapid diffusion in enhancement. Though the two activities were technically complementary, they are only weakly related in their dispersion across geography or industry. Each provides distinct strategic and productivity benefits to private firms. Each should be the focus of distinct economic policies. The economic transactions associated with participation diffused quickly. As of late 2000 there was not much room left for growth. Its diffusion both took advantage of existing capital and motivated additional expenditure on 
software, hardware and networking service. In addition, the dispersion associated with participation became table stakes for most firms, a necessity for doing business. We conclude that if there was an economic benefit to GDP as a result of participation, it was a one-time benefit affiliated with outfitting establishments with the equipment to support participating in email and browsing.

Enhancement diffused less widely and its diffusion may be far from over. As opposed to participation, enhancement was optional--motivated by the development of competitive advantageand it had variable benefits and co-invention costs. There are strong hints in our results that the incidence of these costs and benefits fell primarily on traditionally intensive users of computers. If there is an economic benefit to GDP as a result of enhancement, these benefits were widely dispersed, but dependent on industry. There is still a large possibility that the economic gains will manifest itself in the future. This conclusion also varies with standard approaches to measuring productivity from investment in information technology, where prevailing research makes no allowance for the composition of capital, nor its motivation.

Finally, while we found GPT theory useful for formulating our measurement framework, we relied on the principle that dispersion should reflect economic constraints that foster different behavior across industry and location. These constraints are necessarily localized in contemporary experience. Therefore, we speculate that historical comparisons of the dispersion of the Internet with the dispersion of other GPTs are apt to be badly posed unless the comparisons are heavily qualified. It is misleading to compare the diffusion of the Internet with agricultural improvements, the railroad, electrical networks, telegraph, telephone or PC without accounting for the unique factors that shape co-invention costs and produce dispersion in each episode. Although aspects of similar economic issue arise in historical cases, the Internet's combination of economic motives, speeds, and environments has no precise historical precedent.

\subsection{Dispersion and regional economic growth}


We motivated this study with the assumption that the diffusion of Internet technology does have consequences for comparative regional economic growth. We were careful to provide links between private economic incentives for adoption and regional consequences. We conclude that the link is easily misunderstood without careful examination of commercial adoption behavior.

The economic use and dispersion of Internet technology are often characterized in terms of very limited regional rivalries, such as between Silicon Alley and Silicon Valley and Route 128. Tendencies toward localized commercial "boosterism" favor such a framing and often dominate popular discussion. Previous studies emphasizing concentrated dispersion of technology reinforce the examination of regional rivalries. This is an analytical error in four senses.

First, it is factually incorrect to characterize regional rivalry in use of the Internet as if use were concentrated. Second, analysis of discrete rivalries between two locations can confuse analysis of regional concentration in output markets with concentration in input markets. In this case, there is little concentration in the input market. There are over a dozen different industries comprised of thousands of establishments - from printing to information to finance to warehousing -- intensively using a new technology, such as the Internet. In this setting, any particular regional rivalry in output is of minor relevance to economy-wide outcomes in the use of inputs. For example, the rivalry between Silicon Alley and Silicon Valley in producing Internet content is irrelevant to whether most of the country benefits from the Internet's use in warehousing or insurance contracting. To be sure, the labor markets for supplying Internet technology to warehouses and printing establishments and financial firms may either positively or negatively reinforce each other at a geographically local level (e.g., create knowledge that is useful in both domains or bid up wages for scarce talent), but this phenomenon requires an analytical treatment distinct from the one for output markets.

Third, analysis of discrete rivalries often focuses on the wrong policy question. Standard analysis supports economic policies for alleviating divisions -- a real problem for a minority of 
locations -- and neglects policy questions that assume disperse use of technology, which is the issue facing the majority of locations. That is, dispersion changes competitive policies, because a common facet to business growth - in this case, advanced Internet technology - is quickly becoming the new table stakes for business. These table stakes cannot determine the outcome of regional competitive advantage. That is, when many areas are comparatively similar in terms of use of the GPT and coinventive activities, they compete on similar terms. Regional rivalry then will be determined by the less common factors - other than the Internet (Furman, Porter, and Stern 2002). The proper framing for regional development policy for most locations should begin with such a premise.

Fourth, and related, failing to account for dispersion of technologies leads to misleading economic measurement for policy. A widely dispersed input can be essential for competitive rivalry and yield little direct productivity benefit. That is, if a firm must adopt common technology to match rivals, such a technology usually will not yield higher profits, nor, if the gains in price are competed away, necessarily more value-added in that industry in that location. The key benefit to technology adoption accrues to buyers of final output markets, or from an unmeasurable benefit to suppliers, that is, the losses avoided. Statistics about regional growth, therefore, are apt to be misleading. Participation in one region should not yield measurable productive advance compared to the vast majority of regions who are also participating. Regional productivity might be linked to the investment of local firms in technology that provides competitive advantage, but this economic phenomenon, once again, requires an understanding of the comparative achievement of competing establishments across regions.

We conclude that research focused on concentration or digital divides - heretofore a central concern of the literature on Internet geography—is a misleading basis for formulating regional economic policy about Internet use in business. To be sure, the concerns about low growth are real for the areas in which adoption lags, but economic policy for laggards has little to do with the 
majority of areas, which do not lag. Policies for regional development in most places should devote attention to the factors that are rare and possibly complementary to the use of the Internet for competitive advantage (e.g., such as immobile skilled labor, see Feldman 2002, Kolko, 2002). Bottlenecks in complementary factors will determine regional rivalry in the future.

\subsection{Further research}

The US government statistical agencies have the apparatus - though perhaps not the funding to collect comprehensive data about the behavior of commercial establishments. We find it remarkable that there are no plans to generate comprehensive statistics at any government agency, nor any plans at the Census even to follow up on its extensive survey of manufacturing. Without such data there are only indirect statistical means available for computing the contribution of the Internet to the GDP, capital accumulation, or productivity growth. ${ }^{33}$ Recent private studies are commendable for their attempts to understand the use of Internet in business or the size of the Internet economy by extrapolating from selected surveys. ${ }^{34}$ Extrapolation is the best any research can do when there is no data, but comprehensive data is better.

We show the value of collecting such data. In this study we focus on aggregate trends in the dispersion of Internet technology. But this represents only the beginning of uses for such data. Our study raises many questions about the microdeterminants of use of this GPT. Our conclusion begs the question of why some industries use Internet technology more intensively. While we show that the identities of leading industries tended to be the same over decades, we did not offer an explanation for this phenomenon. Why did the dispersion of the Internet not alter these rankings except in a few industries? What does this say about the strategic benefits to using the Internet and the co-inventive expenses during this GPT's diffusion in comparison to those of the past?

\footnotetext{
${ }^{33}$ See e.g., Atrostic and Gates (2001), Census (2001), Stiroh (2002b).

${ }^{34}$ See e.g., Varian et. al. 2001, Whinston et. al. 2001; Kraemer, Dedrick, and Dunkle 2002.
} 
We also did not measure a third of all employment, namely, small commercial establishments of less than 100 employees. We conjecture that these establishments follow similar patterns in participation and different patterns in enhancement, but this is an open question. We also raised questions about the medium- to large-scale firms in our sample. Do co-invention costs differ between single- and multi-establishment organizations? Between different applications of enhancement? What part of co-invention costs are attributable to local economic factors and what parts are attributable to costs imposed by competition between establishments from similar industries? Forman (2002) offers a framework for addressing these questions using microlevel data, which is a step in the right direction.

Our study also raises questions about the distribution of the economic impact from the use of the Internet. How did local and industrial applications influence the intensity of use of information technology? To what extent can state and local development policies foster a positive environment for lowering these costs? There is room for much economic research applying the estimates in our study to models of regional growth. 


\section{References}

Ames, Edward, and Nathan Rosenberg, 1984. Technological change in the machine tool industry, 1840-1910. In Nathan Rosenberg, ed. Perspectives on Technology, $2^{\text {nd }}$ Edition. Cambridge press, Cambridge MA.

Atrostic, Barbara, K., and John Gates. 2001. U.S. Productivity and Electronic Business Processes in Manufacturing. Working Paper \#01-11. Center for Economic Studies, US Census Bureau.

Atrostic, Barbara K., John Gates, and Ron Jarmin. 2000. Measuring the Electronic Economy: Current Status and Next Steps.. Working Paper \#00-10. Center for Economic Studies, US Census Bureau.

Atrostic, Barbara, K., and Sang V. Nguyen. 2002. Computer Networks and U.S. Manufacturing Plant Productivity: New Evidence from the CNUS Data. Working Paper \#02-01. Center for Economic Studies, US Census Bureau.

Bresnahan, Timothy, and Shane Greenstein. 1997. Technical Progress in Computing and in the Uses of Computers. Brookings Papers on Economic Activity, Microeconomics, 1-78.

Bresnahan, Timothy, and Shane Greenstein. 2001. The economic contribution of information technology: Towards comparative and user studies, Journal of Evolutionary Economics, v11, pp 95118.

Bresnahan, Timothy, and Manuel Trajtenberg. 1995. General Purpose Technologies: 'Engines of Growth'? Journal of Econometrics. 65 (1): 83-108.

Bresnahan, Timothy, Erik Brynjolfsson, and Lorin Hitt. 2002. Information Technology, Work Organization, and the Demand for Skilled Labor: Firm-Level Evidence. Quarterly Journal of Economics 117 (February): 339-376.

Cairncross, Frances, 1997. The Death of Distance. Cambridge, MA: Harvard University Press.

Carlton, Dennis and Judith Chevalier. 2001. Free Riding and Sales Strategies for the Internet. Journal of Industrial Economics. 49 (December): 441-461.

Castells, Manuel, 2002. The Internet Galaxy, Reflections on the Internet, Business and Society, Oxford University Press.

Census. 2001. Home Computers and Internet Use in the United States: August 2000. Survey Release from the United States Department of Commerce. See www.census.gov/epcd/www/ebusiness.htm.

Census. 2002. Detailing Tabulations of Manufacturing E-Business Process Use in 2000. Survey Release from United States Department of Commerce. See www.census.gov/epcd/www/ebusiness.htm.

Charles, S., M. Ives, and A. Leduc. 2002. Embracing E-Business: Does Size Matter? Research Report, Statistics Canada. 
Cherry, Barbara, Alan H. Hammond, and Steve Wildman, 1999. Making Universal Service Policy: Enhancing the Process Through Multidisciplinary Evaluation. Mahwah, NJ: Lawrence Erlbaum Associates.

Choi, Soon-Yong, and Andrew Whinston. 2000. The Internet Economy: Technology and Practice. Austin: SmartEcon Publishing.

Compaine, Benjamin, 2001. The Digital Divide: Facing a Crisis or Creating a Myth? Cambridge, MA: MIT Press.

Cortada, James W., 1996, Information Technology as Business History: Issues in the History and Management of Computers. Westport, CT: Greenwood Press.

Federal Communications Commission, 2002, Form 477 Reporting Requirements \& Deployment Data, http://www.fcc.gov/broadband/data.html

Feldman, Maryann P., 2002. The Internet Revolution and the Geography of Innovation. Forthcoming in International Social Sciences Review Journal.

Fichman, Robert, and Chris Kemerer. 1997. The Assimilation of Software Process Innovations: An Organizational Learning Perspective. Management Science. 43 (October): 1345-1363.

Fichman, Robert, and Chris Kemerer. 1999. The Illusory Diffusion of Innovation: An Examination of Assimilation Gaps. Information Systems Research. 10 (September): 255-275.

Forman, Chris, 2002. The Corporate Digital Divide: Determinants of Internet Adoption. Mimeo. Carnegie Mellon University.

Fraumeni, Barbara, 2001, “E-Commerce: Measurement and Measurement Issues.” American Economic Review, May.

Furman, Jeffrey L., Michael Porter, and Scott Stern, 2002. The Determinants of National Innovative Capacity. Research Policy 31(6): 899-933.

Gertner, Robert, and Robert Stillman. 2001. Vertical Integration and Internet Strategies in the Apparel Industry. Journal of Industrial Economics. 49 (December): 415-440.

Goolsbee, Austan, and Peter Klenow, 1999. Evidence on Learning and Network Externalities in the Diffusion of Home Computers. NBER working paper \# 7329.

Gordon, Robert, 2000. Does the "New Economy" Measure up to the Great Inventions of the Past?. Journal of Economic Perspectives 14 (fall), 49-74.

Helpman, Elahanan,1998. General Purpose Technologies and Economic Growth. Cambridge, MA: The MIT Press. 
Hitt, Lorin and Erik Brynjolfsson. 1997. Information Technology and Internal Firm Organization: An Exploratory Analysis Journal of Management Information Systems 14 (Summer): 1-101.

Hubbard, Tom. 2000. “The Demand for Monitoring Technologies: The Case of Trucking.” Quarterly Journal of Economics 116 (May): 533-560.

Jones, Derek, Takao Kato, and Jeffrey Pliskin. 2002. The Nature and the Determinants of New Information Technologies: Evidence from Medium Sized Establishments in Upstate New York. Working Paper presented at the WIDER Conference on The New Economy in Development.

Kalakota, Ravi, and Marci Robinson. 2001. e-Business 2.0: Roadmap for Success. Reading: AddisonWesley.

Kalakota, Ravi, and Andrew Whinston. 1996. Electonic Commerce: A Manager's Guide. AddisonWesley.

Kitchen, R., and Dodge, Martin, and, 2001. 'Placing' cyberspace: why geography still matters. Information Technology, Education and Society, 1(2), 25-46.

Kolko, Jed, 2002, "Silicon Mountains, Silicon Molehills, Geographic Concentration and Convergence of Internet Industries in the US," Economics of Information and Policy.

Kotkin, Joel, 2000. The New Geography: How the Digital Revolution is Reshaping the American Landscape, New York: Random House.

Kraemer, Kenneth, Jason Dedrick, and Debora Dunkle. 2002. E-Commerce: A Mile Wide and an Inch Deep. Working Paper, Center for Research on Information Technology and Organizations (CRITO), University of California, Irvine.

Landefeld, Steven, and Barbara Fraumeni, 2001, Measuring the new Economy, Survey of Current Business, March., pp $23-40$.

Lipsey, Richard, Cliff Bekar, and Kenneth Carlaw. 1998. What Requires Explanation? In General Purpose Technologies and Economic Growth, 15-54, ed. Elhanan Helpman. Cambridge: MIT Press.

Malone, Thomas, Joanne Yates, and Robert Benjamin. 1987. Electronic Markets and Electronic Hierarchies. Communications of the ACM 30 (June): 484-497.

Mesenbourg, Thomas. 2001. Measuring Electronic Business: Definitions, Underlying Concepts, and Measurement Plans, mimeo released on http://www.census.gov/epcd/www/ebusines.htm.

Moss, Mitchell L., and Anthony M. Townsend, 1997. Tracking the net: using domain names to measure the growth of the Internet in US cities. Journal of Urban Technology 4(3): 47-60.

National Telecommunications Information Administration, US Department of Commerce, 2001. Falling Through the net: Toward Digital Inclusion. 
Noll, Roger, Dina Older-Aguilar, Gregory Rosston, and Richard Ross, 2001, "The Digital Divide: Definitions, Measurement, and Policy Issues," Paper presented at the American Economics Association Meetings, January 2002.

Porter, Michael, 2000, "Strategy and the Internet," Harvard Business Review.

Rogers, Everett, 1995. The Diffusion of Innovations. Fourth Edition. New York: Free Press.

Saxenian, AnnaLee, 1994. Regional Advantage: Culture and Competition in Silicon Valley and Route 128. Cambridge, MA: Harvard University Press.

Stiroh, Kevin, 2002a. Are ICT Spillovers Driving the New Economy? Review of Income and Wealth, 48(1), 33-57.

Stiroh, Kevin. 2002b. Information Technology and The U.S. Productivity Revival: What do the Industry Data Say? Forthcoming, American Economic Review.

Tan, Margaret and Thompson S.H. Teo, 1998. Factors Influencing the Adoption of the Internet. International Journal of Electronic Commerce. 2 (Spring): 5-18.

U.S. Department of Agriculture, 2001, Farm Computer Usage and Ownership Report, 07.30.01, http://usda.mannlib.cornell.edu/reports/nassr/other/computer/

Varian, Hal, Robert E. Litan, Andrew Elder, and Jay Shutter, 2001. The Net Impact Study. www.netimpactstudy.com.

Whinston, Andrew, Anitesh Barua, Jay Shutter, and Brant Wilson. Measuring the Internet Economy; available from http://www.internetindicators.com/jan 2001.pdf.

Zooks, Matthew, 2000a, "Internet Metrics: Using Hosts and Domain Counts to Map the Internet Globally," Telecommunications Policy, 24, 6/7.

Zooks, Matthew, 2000b, "The Web of Production: the Economic Geography of Commercial Interent Content Production in the United States," Environment and Planning, 32: 411-26. 
Table 1

Descriptive Statistics

\begin{tabular}{|l|r|r|r|c|}
\hline Variable & Mean & Std. Dev. & Minimum & Maximum \\
\hline Employment & 310.90 & 600.81 & 100 & 56,000 \\
\hline PCs per employee & 0.37 & 0.53 & 0 & 26.92 \\
\hline Part of multi-establishment firm? & 0.45 & 0.50 & 0 & 1 \\
\hline Member of Fortune 1000? & 0.27 & 0.44 & 0 & 1 \\
\hline Has ticker symbol? & 0.33 & 0.47 & 0 & 1 \\
\hline Has LAN? & 0.57 & 0.49 & 0 & 1 \\
\hline Has mainframe? & 0.04 & 0.19 & 0 & 1 \\
\hline $\begin{array}{l}\text { Has workstation, minicomputer, or } \\
\text { mainframe? }\end{array}$ & 0.39 & 0.49 & & 0 \\
\hline
\end{tabular}

Number of observations $=86,879$ 
Table 2: Harte Hanks Sample Versus the Census of Business Establishments

\begin{tabular}{|c|c|c|}
\hline & Sample & Census \\
\hline \# establishments over 100 employees & 86,879 & 168,372 \\
\hline$\%$ MSA & $82.5 \%$ & $86.7 \%$ \\
\hline$\%$ CMSA & $37.2 \%$ & $42.5 \%$ \\
\hline$\%>500$ employees given have 100 employees & $12.7 \%$ & $10.6 \%$ \\
\hline$\%$ Northeast & $17.7 \%$ & $19.6 \%$ \\
\hline \% Midwest & $27.9 \%$ & $25.5 \%$ \\
\hline$\%$ South & $34.8 \%$ & $34.0 \%$ \\
\hline$\%$ West & $19.6 \%$ & $21.0 \%$ \\
\hline $\begin{array}{l}\% \text { Agriculture, Forestry, Fishing and Hunting } \\
\text { (NAICS }=11 \text { ) }\end{array}$ & $0.2 \%$ & $0.1 \%$ \\
\hline $\begin{array}{l}\text { \% Mining } \\
(\text { NAICS }=21)\end{array}$ & $0.6 \%$ & $0.5 \%$ \\
\hline $\begin{array}{l}\% \text { Utilities } \\
(\text { NAICS }=22)\end{array}$ & $0.8 \%$ & $0.8 \%$ \\
\hline $\begin{array}{l}\% \text { Construction } \\
(\mathrm{NAICS}=23)\end{array}$ & $2.9 \%$ & $4.1 \%$ \\
\hline $\begin{array}{l}\text { \% manufacturing } \\
(\mathrm{NAICS}=31,32,33)\end{array}$ & $27.9 \%$ & $20.8 \%$ \\
\hline $\begin{array}{l}\text { \% Wholesale Trade } \\
(\text { NAICS }=42)\end{array}$ & $6.0 \%$ & $4.8 \%$ \\
\hline $\begin{array}{l}\text { \% Retail Trade } \\
(\mathrm{NAICS}=44,45)\end{array}$ & $17.1 \%$ & $14.7 \%$ \\
\hline $\begin{array}{l}\% \text { Transportation \& Warehousing } \\
(\mathrm{NAICS}=48,49)\end{array}$ & $2.9 \%$ & $3.1 \%$ \\
\hline $\begin{array}{l}\% \text { Media, Telecommunications and Data Processing } \\
(\text { NAICS }=51)\end{array}$ & $3.7 \%$ & $3.7 \%$ \\
\hline $\begin{array}{l}\% \text { Finance and Insurance } \\
(\mathrm{NAICS}=52)\end{array}$ & $4.5 \%$ & $4.6 \%$ \\
\hline $\begin{array}{l}\% \text { Real Estate and Rental and Leasing } \\
(\text { NAICS }=53)\end{array}$ & $0.5 \%$ & $1.0 \%$ \\
\hline $\begin{array}{l}\text { \% Professional, Scientific and Technical Services } \\
\text { (NAICS }=54 \text { ) }\end{array}$ & $5.2 \%$ & $5.0 \%$ \\
\hline $\begin{array}{l}\text { \% Management of Companies and Enterprises } \\
(\mathrm{NAICS}=55)\end{array}$ & $0.3 \%$ & $3.2 \%$ \\
\hline $\begin{array}{l}\% \text { Administrative and Support and Waste Management and } \\
\text { Remediation Services (NAICS }=56 \text { ) }\end{array}$ & $2.7 \%$ & $10.2 \%$ \\
\hline $\begin{array}{l}\% \text { Educational Services } \\
(\text { NAICS }=61)\end{array}$ & $0.01 \%$ & $1.2 \%$ \\
\hline $\begin{array}{l}\% \text { Health Care and Social Assistance } \\
(\text { NAICS }=62 \text { ) }\end{array}$ & $16.7 \%$ & $12.8 \%$ \\
\hline $\begin{array}{l}\% \text { Arts, Entertainment, and Recreation } \\
(\mathrm{NAICS}=71)\end{array}$ & $1.6 \%$ & $1.5 \%$ \\
\hline $\begin{array}{l}\% \text { Accommodation and Food Services } \\
(\text { NAICS }=72)\end{array}$ & $5.5 \%$ & $5.1 \%$ \\
\hline $\begin{array}{l}\% \text { Other Services (except Public Administration) } \\
\text { (NAICS }=81 \text { ) }\end{array}$ & $0.9 \%$ & $2.2 \%$ \\
\hline
\end{tabular}


Table 3:

National Internet Adoption Rates

(in percentages)

\begin{tabular}{|l|c|c|c|c|c|c|}
\hline & $\begin{array}{c}\text { Weighted } \\
\text { Average }\end{array}$ & $\begin{array}{c}\text { Unweighted } \\
\text { Average }\end{array}$ & Northeast & Midwest & South & West \\
\hline Participation & $88.6 \%$ & $80.7 \%$ & $88.0 \%$ & $88.7 \%$ & $89.0 \%$ & $85.7 \%$ \\
\hline Enhancement & $12.6 \%$ & $11.2 \%$ & $12.7 \%$ & $12.7 \%$ & $12.4 \%$ & $12.5 \%$ \\
\hline $\begin{array}{l}\text { Enhancement \& } \\
\text { experimenting with } \\
\text { enhancement }\end{array}$ & $23.2 \%$ & $18.1 \%$ & $24.0 \%$ & $23.1 \%$ & $22.7 \%$ & $23.3 \%$ \\
\hline
\end{tabular}




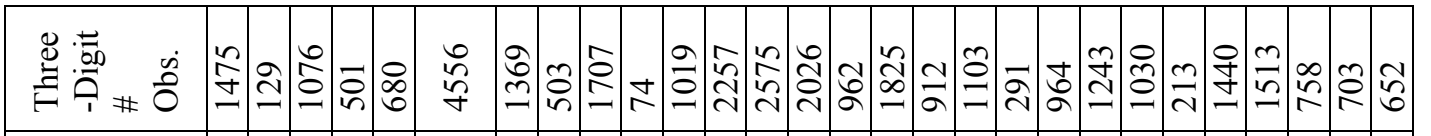

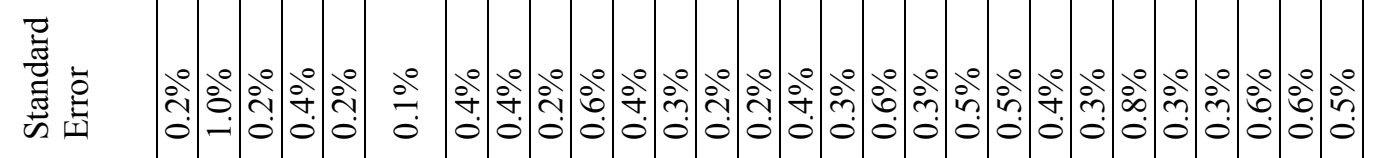

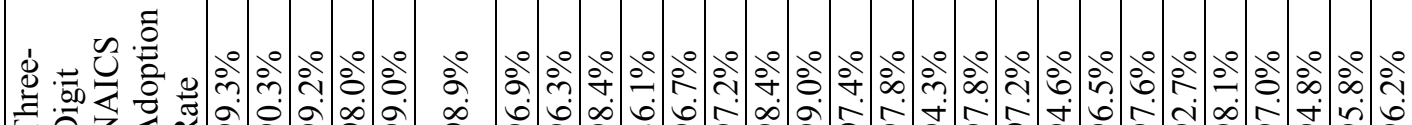

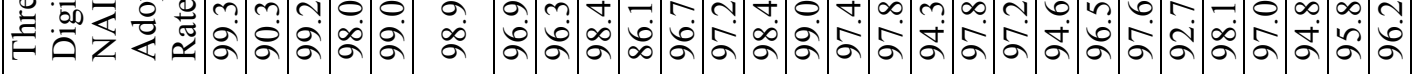

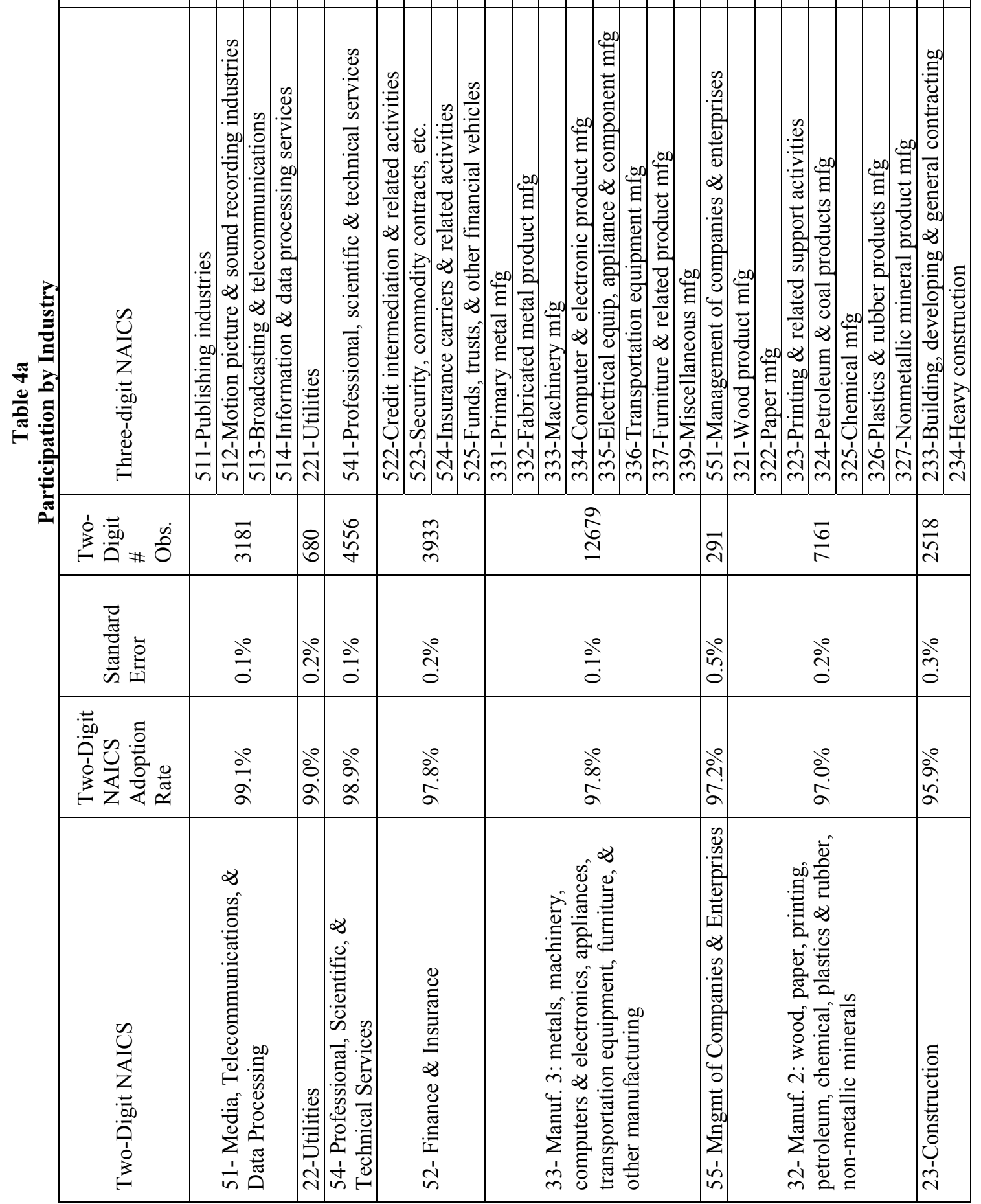




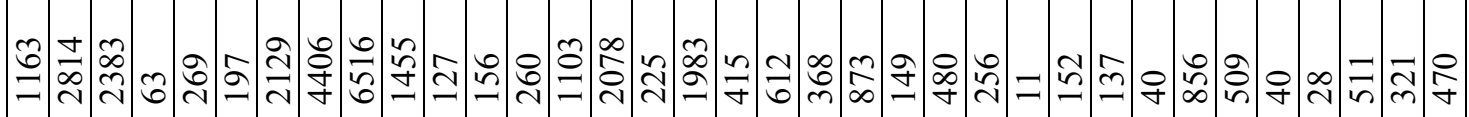

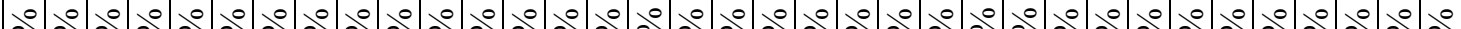
ஸ்

.

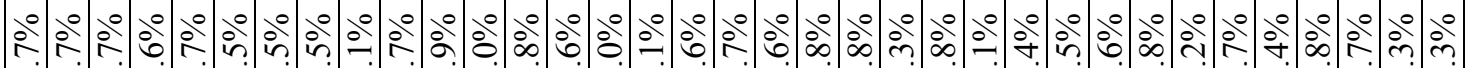

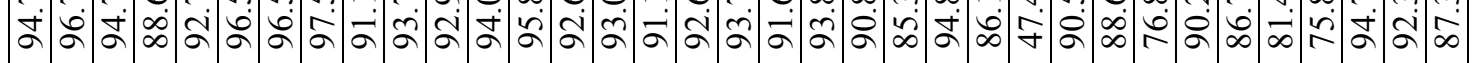

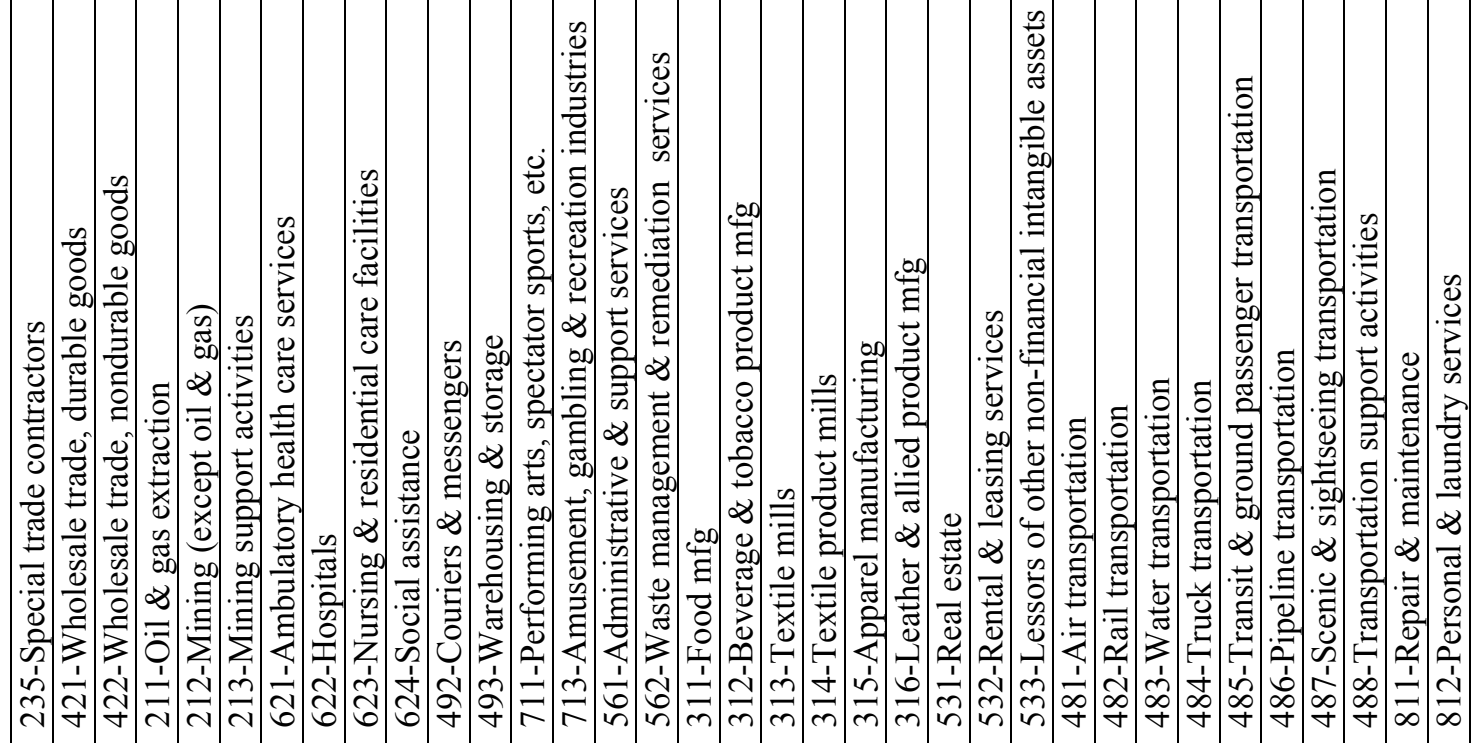

\begin{tabular}{|c|c|c|c|c|c|c|c|c|c|}
\hline$\hat{\hat{a}}$ & సิ & 号 & $\stackrel{\infty}{\sim}$ & $\begin{array}{l}\hat{0} \\
=\end{array}$ & $\begin{array}{r}\tilde{\vartheta} \\
\hat{n}\end{array}$ & \& & $\hat{\sigma}$ & 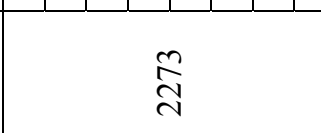 & $\bar{\Omega}$ \\
\hline$\stackrel{\text { ஸे }}{0}$ & $\stackrel{\dot{0}}{\circ}$ & $\stackrel{\circ}{\stackrel{0}{0}}$ & $\stackrel{\text { ̊े }}{\circ}$ & $\stackrel{\text { i̊n }}{0}$ & $\stackrel{\circ}{n}$ & $\stackrel{\stackrel{0}{+}}{\stackrel{0}{0}}$ & $\stackrel{\text { ठे }}{\text { ठे }}$ & $\stackrel{\circ}{n}$ & $\begin{array}{l}\stackrel{0}{0} \\
\stackrel{0}{0}\end{array}$ \\
\hline $\begin{array}{l}\stackrel{0}{\infty} \\
\text { aे }\end{array}$ & $\begin{array}{l}\dot{d} \\
\dot{b} \\
\ddot{a}\end{array}$ & $\frac{\partial^{\circ}}{\sigma^{\circ}}$ & $\begin{array}{l}\dot{b}_{0}^{\circ} \\
\text { aे }\end{array}$ & $\begin{array}{l}\dot{b} \\
\dot{a}\end{array}$ & $\begin{array}{l}\text { ลें } \\
\text { ूं }\end{array}$ & $\begin{array}{c}\stackrel{0}{\hat{~}} \\
\text { ă }\end{array}$ & iें & $\begin{array}{l}\stackrel{\circ}{0} \\
\text { ๙̇ }\end{array}$ & $\begin{array}{l}\stackrel{0}{i} \\
\text { å }\end{array}$ \\
\hline 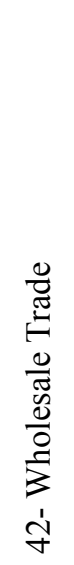 & 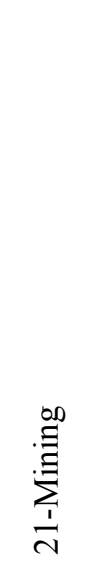 & 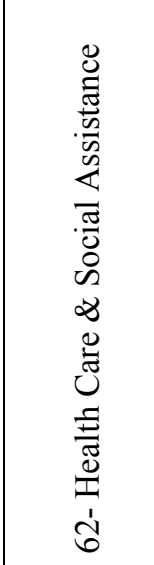 & 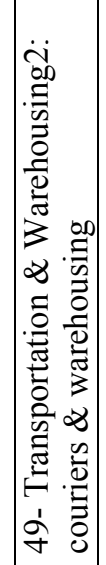 & 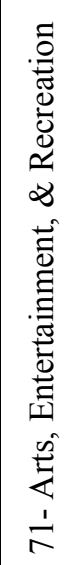 & 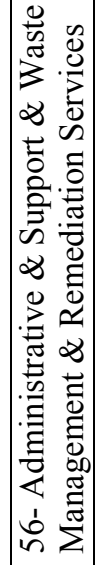 & 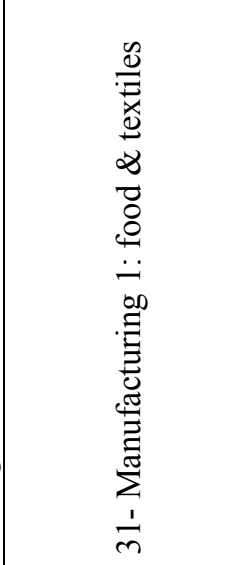 & 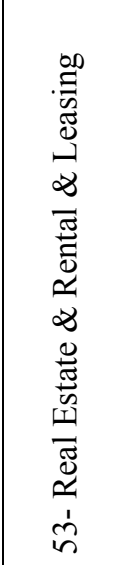 & 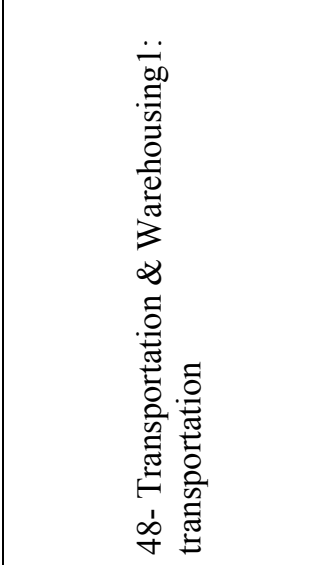 & 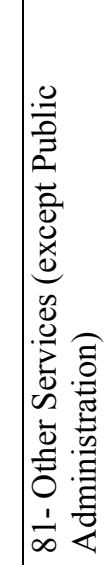 \\
\hline
\end{tabular}




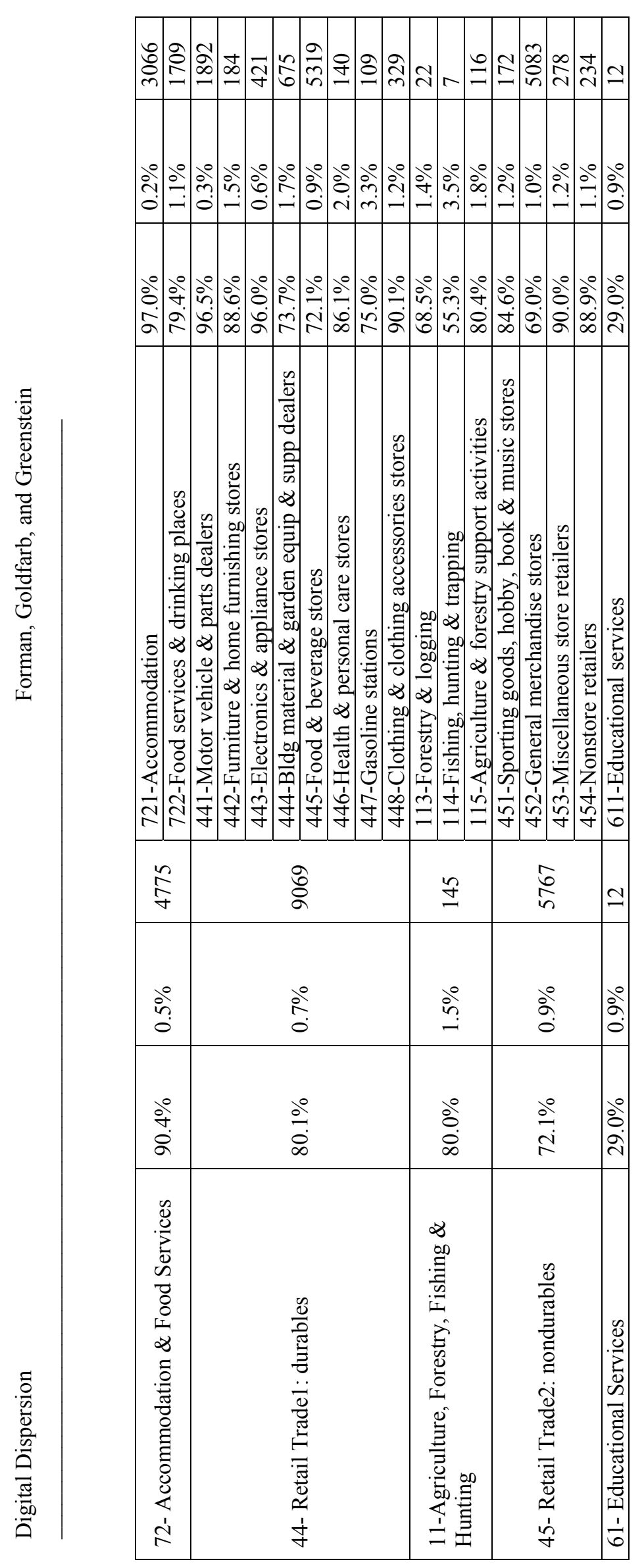




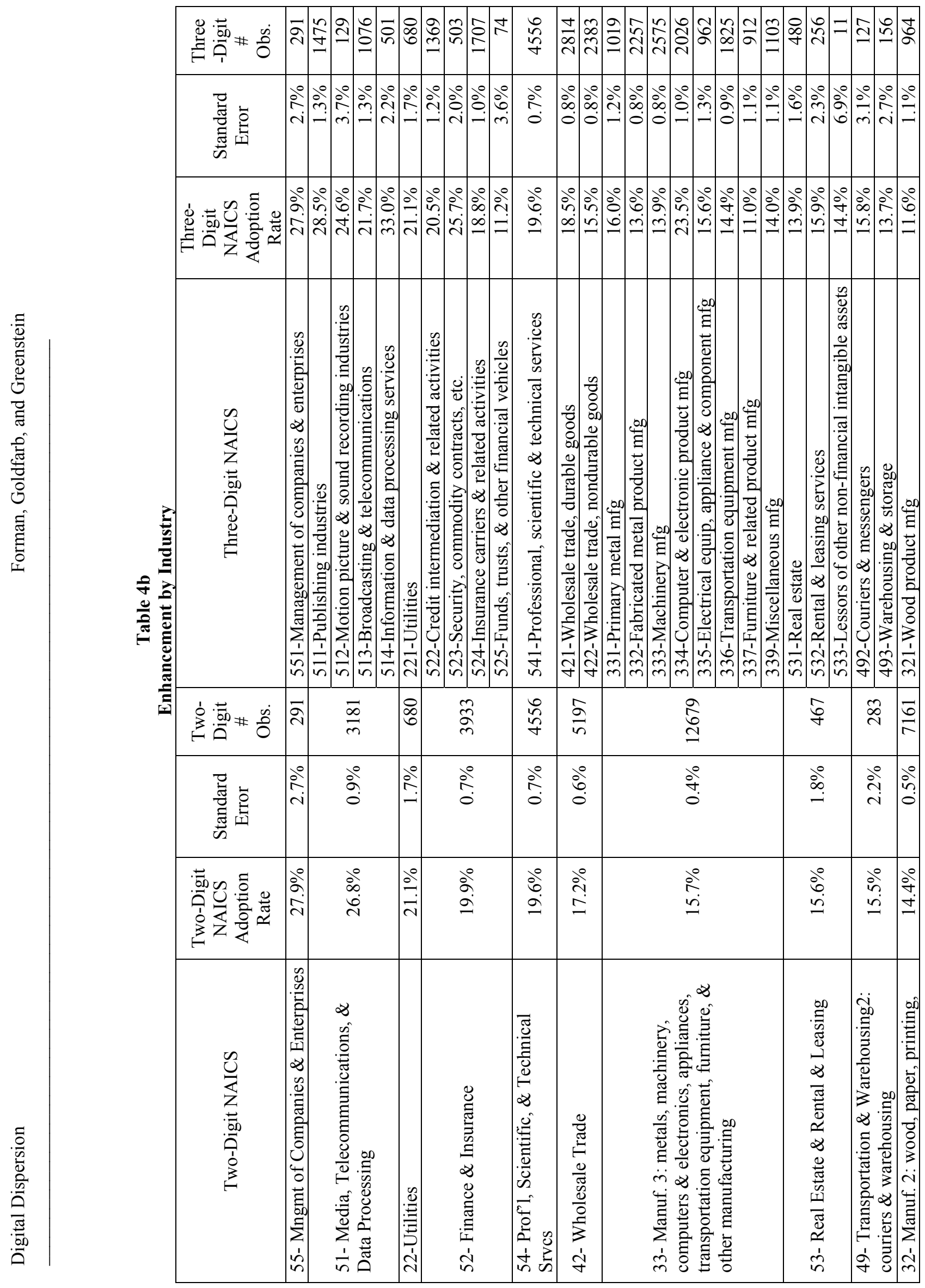




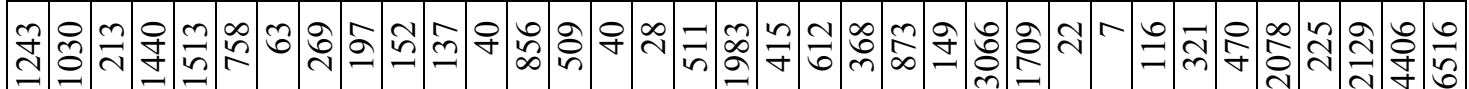

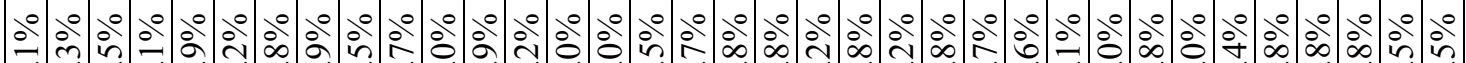

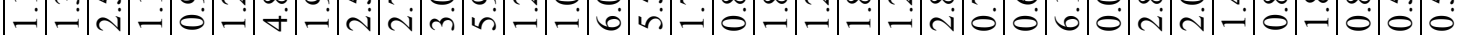

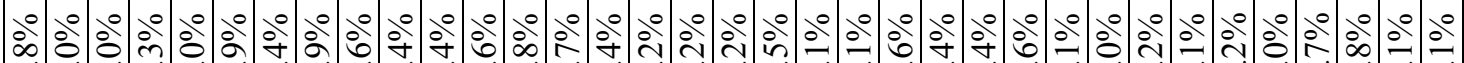

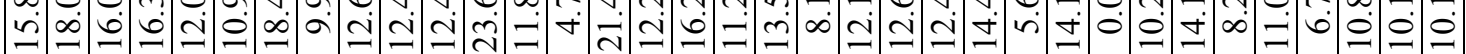

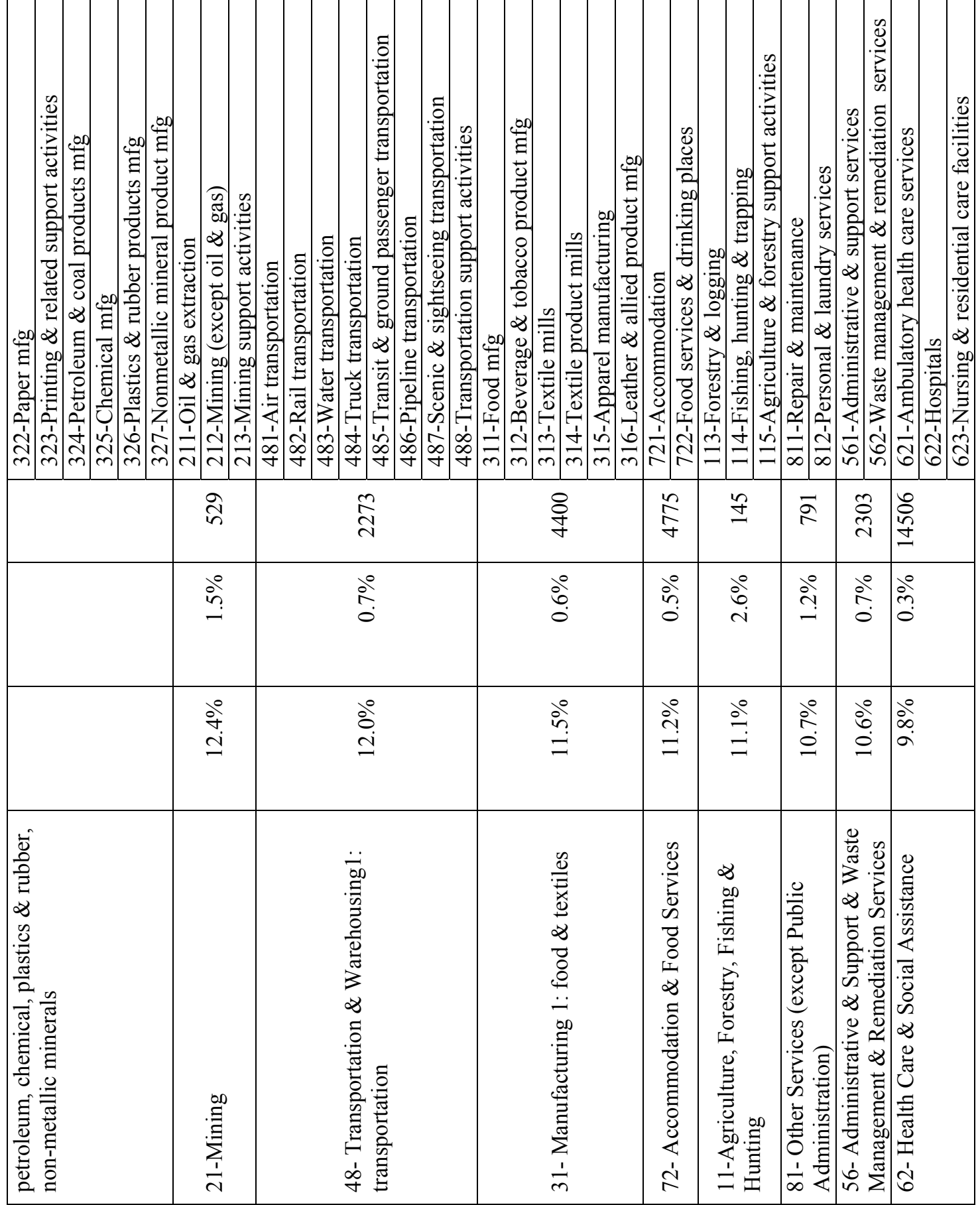




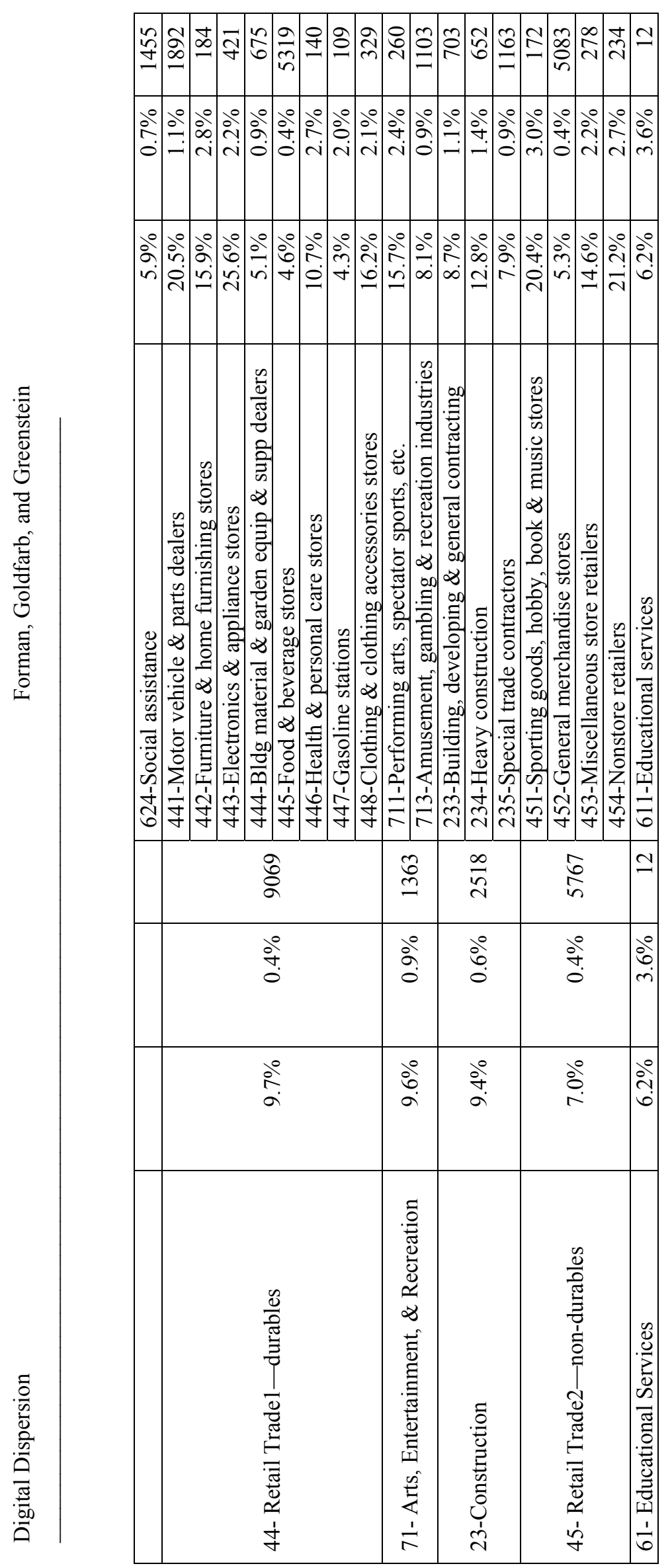


Table 5a: Participation Among Metropolitan Areas with Over One Million People

\begin{tabular}{|c|c|c|c|c|c|}
\hline Rank & City & Rate & Std Error & Obs & Population \\
\hline 1 & San Francisco--Oakland--San Jose, CA & $96.4 \%$ & $0.4 \%$ & 2135 & $7,039,362$ \\
\hline 2 & Denver--Boulder--Greeley, CO & $95.9 \%$ & $0.7 \%$ & 940 & $2,581,506$ \\
\hline 3 & Cleveland--Akron, $\mathrm{OH}$ & $94.8 \%$ & $0.6 \%$ & 1099 & $2,945,831$ \\
\hline 4 & Seattle--Tacoma--Bremerton, WA & $93.9 \%$ & $0.5 \%$ & 1012 & $3,554,760$ \\
\hline 5 & Salt Lake City--Ogden, UT & $93.5 \%$ & $0.8 \%$ & 535 & $1,333,914$ \\
\hline 6 & San Antonio, TX & $93.3 \%$ & $0.8 \%$ & 395 & $1,592,383$ \\
\hline 7 & Providence--Fall River--Warwick, RI--MA & $93.0 \%$ & $1.2 \%$ & 290 & $1,188,613$ \\
\hline 8 & Grand Rapids--Muskegon--Holland, MI & $93.0 \%$ & $0.7 \%$ & 503 & $1,088,514$ \\
\hline 9 & Minneapolis--St. Paul, MN--WI & $92.7 \%$ & $0.5 \%$ & 1411 & $2,968,806$ \\
\hline 10 & Los Angeles--Riverside--Orange County, CA & $92.5 \%$ & $0.4 \%$ & 4099 & $16,373,645$ \\
\hline 11 & Kansas City, MO--KS & $92.2 \%$ & $0.6 \%$ & 753 & $1,776,062$ \\
\hline 12 & Austin--San Marcos, TX & $92.1 \%$ & $0.7 \%$ & 344 & $1,249,763$ \\
\hline 13 & Dallas--Fort Worth, TX & $92.1 \%$ & $0.5 \%$ & 1720 & $5,221,801$ \\
\hline 14 & Portland--Salem, OR--WA & $92.1 \%$ & $0.6 \%$ & 776 & $2,265,223$ \\
\hline 15 & Houston--Galveston--Brazoria, TX & $91.7 \%$ & $0.6 \%$ & 1413 & $4,669,571$ \\
\hline 16 & Phoenix--Mesa, AZ & $91.6 \%$ & $0.7 \%$ & 988 & $3,251,876$ \\
\hline 17 & Raleigh--Durham--Chapel Hill, NC & $91.6 \%$ & $0.9 \%$ & 398 & $1,187,941$ \\
\hline 18 & Columbus, $\mathrm{OH}$ & $91.5 \%$ & $0.9 \%$ & 574 & $1,540,157$ \\
\hline 19 & Milwaukee--Racine, WI & $91.5 \%$ & $0.7 \%$ & 855 & $1,689,572$ \\
\hline 20 & San Diego, CA & $91.5 \%$ & $0.7 \%$ & 738 & $2,813,833$ \\
\hline 21 & Detroit-Ann Arbor--Flint, MI & $91.4 \%$ & $0.6 \%$ & 1621 & $5,456,428$ \\
\hline 22 & Indianapolis, IN & $91.3 \%$ & $0.8 \%$ & 646 & $1,607,486$ \\
\hline 23 & Greensboro--Winston-Salem--High Point, NC & $91.1 \%$ & $0.9 \%$ & 570 & $1,251,509$ \\
\hline 24 & Atlanta, GA & $90.9 \%$ & $0.6 \%$ & 1426 & $4,112,198$ \\
\hline 25 & Miami--Fort Lauderdale, FL & $90.9 \%$ & $0.7 \%$ & 1010 & $3,876,380$ \\
\hline 26 & Charlotte--Gastonia--Rock Hill, NC-SC & $90.7 \%$ & $0.9 \%$ & 618 & $1,499,293$ \\
\hline 27 & Boston-Worcester--Lawrence, MA--NH--ME--CT & $90.6 \%$ & $0.5 \%$ & 2231 & $5,819,100$ \\
\hline 28 & Chicago--Gary--Kenosha, IL--IN-WI & $90.5 \%$ & $0.4 \%$ & 3431 & $9,157,540$ \\
\hline 29 & New York--Northern New Jersey--Long Island, NY--NJ--CT--PA & $90.5 \%$ & $0.4 \%$ & 4775 & $21,199,865$ \\
\hline 30 & Washington--Baltimore, DC--MD-VA--WV & $90.4 \%$ & $0.5 \%$ & 2222 & $7,608,070$ \\
\hline 31 & Philadelphia--Wilmington-Atlantic City, PA--NJ-DE--MD & $90.3 \%$ & $0.5 \%$ & 1745 & $6,188,463$ \\
\hline 32 & Rochester, NY & $90.3 \%$ & $1.0 \%$ & 373 & $1,098,201$ \\
\hline 33 & Hartford, CT & $90.2 \%$ & $0.9 \%$ & 500 & $1,183,110$ \\
\hline 34 & Oklahoma City, OK & $90.2 \%$ & $1.1 \%$ & 339 & $1,083,346$ \\
\hline 35 & Memphis, TN--AR--MS & $90.0 \%$ & $1.0 \%$ & 437 & $1,135,614$ \\
\hline 36 & Louisville, KY--IN & $89.9 \%$ & $1.0 \%$ & 448 & $1,025,598$ \\
\hline 37 & Cincinnati--Hamilton, OH--KY-IN & $89.7 \%$ & $0.8 \%$ & 772 & $1,979,202$ \\
\hline 38 & St. Louis, MO--IL & $89.7 \%$ & $0.7 \%$ & 936 & $2,603,607$ \\
\hline 39 & Pittsburgh, PA & $89.1 \%$ & $0.8 \%$ & 727 & $2,358,695$ \\
\hline 40 & Buffalo--Niagara Falls, NY & $88.5 \%$ & $1.1 \%$ & 393 & $1,170,111$ \\
\hline 41 & Tampa--St. Petersburg--Clearwater, FL & $88.4 \%$ & $0.9 \%$ & 812 & $2,395,997$ \\
\hline 42 & Jacksonville, FL & $87.6 \%$ & $1.3 \%$ & 373 & $1,100,491$ \\
\hline 43 & Las Vegas, NV--AZ & $87.2 \%$ & $1.2 \%$ & 417 & $1,563,282$ \\
\hline 44 & Sacramento--Yolo, CA & $87.0 \%$ & $1.2 \%$ & 427 & $1,796,857$ \\
\hline 45 & Norfolk--Virginia Beach--Newport News, VA--NC & $86.9 \%$ & $1.2 \%$ & 374 & $1,569,541$ \\
\hline 46 & New Orleans, LA & $86.0 \%$ & $1.1 \%$ & 386 & $1,337,726$ \\
\hline 47 & West Palm Beach--Boca Raton, FL & $85.9 \%$ & $1.2 \%$ & 299 & $1,131,184$ \\
\hline 48 & Orlando, FL & $85.5 \%$ & $1.0 \%$ & 622 & $1,644,561$ \\
\hline 49 & Nashville, TN & $84.6 \%$ & $1.1 \%$ & 466 & $1,231,311$ \\
\hline
\end{tabular}


Table 5b Enhancement Among Metropolitan Areas with Over One Million People

\begin{tabular}{|c|c|c|c|c|c|}
\hline Rank & City & Rate & Std Error & Obs & Population \\
\hline 1 & Denver--Boulder--Greeley, CO & $18.3 \%$ & $1.3 \%$ & 940 & $2,581,506$ \\
\hline 2 & San Francisco--Oakland--San Jose, CA & $17.0 \%$ & $0.9 \%$ & 2135 & $7,039,362$ \\
\hline 3 & Salt Lake City--Ogden, UT & $16.7 \%$ & $1.7 \%$ & 535 & $1,333,914$ \\
\hline 4 & Minneapolis--St. Paul, MN--WI & $15.9 \%$ & $1.0 \%$ & 1411 & $2,968,806$ \\
\hline 5 & Houston--Galveston--Brazoria, TX & $15.7 \%$ & $1.0 \%$ & 1413 & $4,669,571$ \\
\hline 6 & Atlanta, GA & $15.4 \%$ & $1.0 \%$ & 1426 & $4,112,198$ \\
\hline 7 & Oklahoma City, OK & $15.4 \%$ & $2.0 \%$ & 339 & $1,083,346$ \\
\hline 8 & Dallas--Fort Worth, TX & $15.3 \%$ & $0.9 \%$ & 1720 & $5,221,801$ \\
\hline 9 & San Antonio, TX & $15.3 \%$ & $1.9 \%$ & 395 & $1,592,383$ \\
\hline 10 & Portland--Salem, OR--WA & $15.1 \%$ & $1.3 \%$ & 776 & $2,265,223$ \\
\hline 11 & Providence--Fall River-Warwick, RI--MA & $14.9 \%$ & $2.2 \%$ & 290 & $1,188,613$ \\
\hline 12 & Austin--San Marcos, TX & $14.7 \%$ & $1.9 \%$ & 344 & $1,249,763$ \\
\hline 13 & Cleveland--Akron, $\mathrm{OH}$ & $14.7 \%$ & $1.2 \%$ & 1099 & $2,945,831$ \\
\hline 14 & Tampa--St. Petersburg-Clearwater, FL & $14.6 \%$ & $1.3 \%$ & 812 & $2,395,997$ \\
\hline 15 & Memphis, TN--AR--MS & $14.5 \%$ & $1.8 \%$ & 437 & $1,135,614$ \\
\hline 16 & Seattle--Tacoma--Bremerton, WA & $14.5 \%$ & $1.2 \%$ & 1012 & $3,554,760$ \\
\hline 17 & Hartford, CT & $14.4 \%$ & $1.6 \%$ & 500 & $1,183,110$ \\
\hline 18 & San Diego, CA & $14.3 \%$ & $1.3 \%$ & 738 & $2,813,833$ \\
\hline 19 & Cincinnati--Hamilton, $\mathrm{OH}-\mathrm{KY}$--IN & $14.2 \%$ & $1.3 \%$ & 772 & $1,979,202$ \\
\hline 20 & Washington--Baltimore, DC-MD-VA--WV & $14.2 \%$ & $0.8 \%$ & 2222 & $7,608,070$ \\
\hline 21 & Chicago--Gary--Kenosha, IL-IN--WI & $14.1 \%$ & $0.7 \%$ & 3431 & $9,157,540$ \\
\hline 22 & Rochester, NY & $14.1 \%$ & $1.9 \%$ & 373 & $1,098,201$ \\
\hline 23 & Boston--Worcester--Lawrence, MA--NH--ME--CT & $13.9 \%$ & $0.8 \%$ & 2231 & $5,819,100$ \\
\hline 24 & Detroit--Ann Arbor--Flint, MI & $13.8 \%$ & $0.9 \%$ & 1621 & $5,456,428$ \\
\hline 25 & Kansas City, MO--KS & $13.7 \%$ & $1.3 \%$ & 753 & $1,776,062$ \\
\hline 26 & Raleigh--Durham--Chapel Hill, NC & $13.7 \%$ & $1.7 \%$ & 398 & $1,187,941$ \\
\hline 27 & Pittsburgh, PA & $13.6 \%$ & $1.3 \%$ & 727 & $2,358,695$ \\
\hline 28 & Indianapolis, IN & $13.6 \%$ & $1.4 \%$ & 646 & $1,607,486$ \\
\hline 29 & Charlotte-Gastonia--Rock Hill, NC--SC & $13.6 \%$ & $1.5 \%$ & 618 & $1,499,293$ \\
\hline 30 & West Palm Beach--Boca Raton, FL & $13.6 \%$ & $2.0 \%$ & 299 & $1,131,184$ \\
\hline 31 & Los Angeles--Riverside-Orange County, CA & $13.5 \%$ & $0.6 \%$ & 4099 & $16,373,645$ \\
\hline 32 & Miami-Fort Lauderdale, FL & $13.5 \%$ & $1.1 \%$ & 1010 & $3,876,380$ \\
\hline 33 & New York--Northern New Jersey--Long Island, NY-NJ-CT-PA & $13.5 \%$ & $0.6 \%$ & 4775 & $21,199,865$ \\
\hline 34 & Philadelphia--Wilmington-Atlantic City, PA--NJ--DE--MD & $13.3 \%$ & $0.9 \%$ & 1745 & $6,188,463$ \\
\hline 35 & St. Louis, MO--IL & $13.2 \%$ & $1.2 \%$ & 936 & $2,603,607$ \\
\hline 36 & Louisville, KY--IN & $13.2 \%$ & $1.6 \%$ & 448 & $1,025,598$ \\
\hline 37 & Columbus, $\mathrm{OH}$ & $13.0 \%$ & $1.5 \%$ & 574 & $1,540,157$ \\
\hline 38 & Buffalo-Niagara Falls, NY & $12.9 \%$ & $1.7 \%$ & 393 & $1,170,111$ \\
\hline 39 & Phoenix-Mesa, AZ & $12.4 \%$ & $1.1 \%$ & 988 & $3,251,876$ \\
\hline 40 & Greensboro-Winston-Salem-High Point, NC & $12.2 \%$ & $1.4 \%$ & 570 & $1,251,509$ \\
\hline 41 & Grand Rapids--Muskegon-Holland, MI & $12.0 \%$ & $1.5 \%$ & 503 & $1,088,514$ \\
\hline 42 & New Orleans, LA & $11.9 \%$ & $1.7 \%$ & 386 & $1,337,726$ \\
\hline 43 & Milwaukee--Racine, WI & $11.7 \%$ & $1.2 \%$ & 855 & $1,689,572$ \\
\hline 44 & Nashville, TN & $11.7 \%$ & $1.5 \%$ & 466 & $1,231,311$ \\
\hline 45 & Jacksonville, FL & $11.3 \%$ & $1.7 \%$ & 373 & $1,100,491$ \\
\hline 46 & Sacramento--Yolo, CA & $11.8 \%$ & $1.6 \%$ & 427 & $1,796,857$ \\
\hline 47 & Norfolk--Virginia Beach-Newport News, VA--NC & $10.8 \%$ & $1.7 \%$ & 374 & $1,569,541$ \\
\hline 48 & Orlando, FL & $10.5 \%$ & $1.3 \%$ & 622 & $1,644,561$ \\
\hline 49 & Las Vegas, NV--AZ & $9.0 \%$ & $1.4 \%$ & 417 & $1,563,282$ \\
\hline
\end{tabular}


Table 6a

Average Adoption by Size of MSA

\begin{tabular}{|c|c|c|c|c|c|}
\hline Population & $\begin{array}{c}\text { Average Participation } \\
\text { by MSA Population }\end{array}$ & $\begin{array}{c}\text { Standard } \\
\text { Error }\end{array}$ & $\begin{array}{c}\text { Average } \\
\text { Enhancement }\end{array}$ & $\begin{array}{c}\text { Standard } \\
\text { Error }\end{array}$ & $\begin{array}{c}\text { Number } \\
\text { of Areas }\end{array}$ \\
\hline$>1$ million & $90.4 \%$ & $0.1 \%$ & $14.7 \%$ & $0.2 \%$ & 57 \\
\hline $250,000-1$ million & $84.9 \%$ & $0.2 \%$ & $11.2 \%$ & $0.3 \%$ & 116 \\
\hline$<250,000$ & $75.5 \%$ & $0.2 \%$ & $9.9 \%$ & $0.3 \%$ & 143 \\
\hline
\end{tabular}

Table 6b

Percentage of Establishments in Top Quartile Industry for Enhancement, by Size of MSA

\begin{tabular}{|c|c|c|c|c|}
\hline Population & $\begin{array}{c}\text { Percentage of } \\
\text { Establishments in } \\
\text { Top Quartile }\end{array}$ & $\begin{array}{c}\text { Percentage of } \\
\text { Establishments in Top } \\
\text { Quartile of Non-retail } \\
\text { Adopters }\end{array}$ & $\begin{array}{c}\text { Percentage of } \\
\text { Establishments } \\
\text { that are } \\
\text { Retailing }\end{array}$ & \# of Areas \\
\hline$>1$ million & $27.5 \%$ & $32.1 \%$ & $14.3 \%$ & 57 \\
\hline $250,000-1$ million & $19.5 \%$ & $23.5 \%$ & $16.7 \%$ & 116 \\
\hline$<250,000$ & $19.0 \%$ & $23.3 \%$ & $18.3 \%$ & 143 \\
\hline
\end{tabular}

TABLE 6c:

Importance of industry and population on enhancement (standard errors in parentheses)

\begin{tabular}{|c|c|c|c|c|c|}
\hline & $\begin{array}{l}\text { (1) } \\
\text { enhancement }\end{array}$ & $\begin{array}{l}\text { (2) } \\
\text { enhancement }\end{array}$ & $\begin{array}{l}\text { (3) } \\
\text { enhancement }\end{array}$ & $\begin{array}{l}\text { (4) } \\
\text { enhancement }\end{array}$ & $\begin{array}{l}\text { (5) } \\
\text { enhancement }\end{array}$ \\
\hline $\begin{array}{l}\text { (a) Percent firms in } \\
\text { top quartile }\end{array}$ & $\begin{array}{l}0.259 * * * \\
(0.0291)\end{array}$ & $\begin{array}{l}0.214 * * * \\
(0.0388)\end{array}$ & $\begin{array}{l}0.200 * * * \\
(0.0498)\end{array}$ & $\begin{array}{l}0.212 * * * \\
(0.0612)\end{array}$ & $\begin{array}{l}0.177 * * * \\
(0.0615)\end{array}$ \\
\hline $\begin{array}{l}\text { (b) MSA population } \\
\text { greater than } 1 \text { million }\end{array}$ & & $\begin{array}{l}0.0127^{*} \\
(0.00719)\end{array}$ & & $\begin{array}{l}0.0189 \\
(0.0221)\end{array}$ & $\begin{array}{l}0.0183 \\
(0.0219)\end{array}$ \\
\hline $\begin{array}{l}\text { (c) MSA pop. between } \\
250,000 \& 1 \text { million }\end{array}$ & & $\begin{array}{l}0.00331 \\
(0.00479) \\
\end{array}$ & & $\begin{array}{l}0.000163 \\
(0.0132)\end{array}$ & $\begin{array}{l}0.00231 \\
(0.0131)\end{array}$ \\
\hline$(\mathrm{a}) *(\mathrm{~b})$ & & & $\begin{array}{l}0.0560 \\
(0.0360)\end{array}$ & $\begin{array}{l}-0.0250 \\
(0.105)\end{array}$ & $\begin{array}{l}-0.0302 \\
(0.103)\end{array}$ \\
\hline$(\mathrm{a}) *(\mathrm{c})$ & & & $\begin{array}{l}0.0238 \\
(0.0322)\end{array}$ & $\begin{array}{l}0.0199 \\
(0.0876)\end{array}$ & $\begin{array}{l}0.00881 \\
(0.0866)\end{array}$ \\
\hline$\%$ retailing & & & & & $\begin{array}{l}-0.187 * * * \\
(0.0622)\end{array}$ \\
\hline Constant & $\begin{array}{l}0.0706 * * * \\
(0.00496)\end{array}$ & $\begin{array}{l}0.0739 * * * \\
(0.00538)\end{array}$ & $\begin{array}{l}0.0758 * * * \\
(0.00598)\end{array}$ & $\begin{array}{l}0.0742 * * * \\
(0.00768)\end{array}$ & $\begin{array}{l}0.112 * * * \\
(0.0146)\end{array}$ \\
\hline R-sq & 0.1995 & 0.2074 & 0.2060 & 0.2079 & 0.2302 \\
\hline
\end{tabular}

$* * *$ significant at $99 \%$ confidence level

**significant at $95 \%$ confidence level

*significant at $90 \%$ confidence level 
Table 7a

Leading Adopters of Enhancement Among MSAs With Over One Million in Population

\begin{tabular}{|c|c|c|c|c|}
\hline MSA & $\begin{array}{r}\text { Adoption } \\
\text { Rate }\end{array}$ & $\begin{array}{r}\text { Standard } \\
\text { Error }\end{array}$ & $\begin{array}{c}\text { Number of } \\
\text { Observations }\end{array}$ & $\begin{array}{l}\text { \% Establishments } \\
\text { in Top Quartile }\end{array}$ \\
\hline San Jose, CA & $20.0 \%$ & $1.6 \%$ & 638 & $33.2 \%$ \\
\hline Denver, $\mathrm{CO}$ & $17.1 \%$ & $1.4 \%$ & 778 & $31.1 \%$ \\
\hline Salt Lake City-Ogden, UT & $16.7 \%$ & $1.7 \%$ & 535 & $26.1 \%$ \\
\hline San Francisco, CA & $16.5 \%$ & $1.5 \%$ & 608 & $39.4 \%$ \\
\hline Houston, TX & $16.2 \%$ & $1.1 \%$ & 1320 & $26.5 \%$ \\
\hline Seattle-Bellevue-Everett, WA & $16.0 \%$ & $1.3 \%$ & 799 & $29.1 \%$ \\
\hline Minneapolis-St. Paul, MN--WI & $15.9 \%$ & $1.0 \%$ & 1411 & $28.2 \%$ \\
\hline Portland-Vancouver, OR--WA & $15.6 \%$ & $1.4 \%$ & 683 & $27.5 \%$ \\
\hline Oklahoma City, OK & $15.4 \%$ & $2.0 \%$ & 339 & $19.7 \%$ \\
\hline Atlanta, GA & $15.4 \%$ & $1.0 \%$ & 1426 & $32.0 \%$ \\
\hline \begin{tabular}{|l|} 
Average of Top Ten large MSAs \\
\end{tabular} & $16.5 \%$ & & & $26.6 \%$ \\
\hline Average of Bottom Ten large MSAs & $10.7 \%$ & & & $21.7 \%$ \\
\hline
\end{tabular}

Table $7 \mathbf{b}$

Leading Adopters of Enhancement Among MSAs With 250,000 to One Million in Population

\begin{tabular}{|c|c|c|c|c|}
\hline MSA & $\begin{array}{r}\text { Adoption } \\
\text { Rate }\end{array}$ & $\begin{array}{r}\text { Standard } \\
\text { Error } \\
\end{array}$ & \begin{tabular}{|c|} 
Number of \\
Observations
\end{tabular} & $\begin{array}{l}\text { \% Establishments } \\
\text { in Top Quartile }\end{array}$ \\
\hline Huntsville, AL & $19.5 \%$ & $3.3 \%$ & 136 & $27.7 \%$ \\
\hline Appleton-Oshkosh-Neenah, WI & $19.4 \%$ & $3.2 \%$ & 150 & $14.4 \%$ \\
\hline El Paso, TX & $18.8 \%$ & $2.8 \%$ & 185 & $15.0 \%$ \\
\hline Boulder-Longmont, CO & $18.4 \%$ & $3.4 \%$ & 121 & $33.8 \%$ \\
\hline Des Moines, IA & $18.0 \%$ & $2.6 \%$ & 234 & $33.7 \%$ \\
\hline Biloxi-Gulfport-Pascagoula, MS & $17.8 \%$ & $4.4 \%$ & 74 & $19.6 \%$ \\
\hline Omaha, NE-IA & $17.3 \%$ & $2.1 \%$ & 343 & $31.6 \%$ \\
\hline Pensacola, FL & $17.1 \%$ & $4.0 \%$ & 86 & $17.1 \%$ \\
\hline Peoria-Pekin, IL & $16.2 \%$ & $3.2 \%$ & 136 & $20.3 \%$ \\
\hline Kalamazoo-Battle Creek, MI & $16.2 \%$ & $2.9 \%$ & 172 & $15.6 \%$ \\
\hline Average of Top Ten Medium MSAs & $17.9 \%$ & & & $24.4 \%$ \\
\hline Average of Bottom Ten Medium MSAs & $4.4 \%$ & & & $16.3 \%$ \\
\hline
\end{tabular}

Table 7c

Leading Adopters of Enhancement Among MSAs With Less Than 250,000 in Population

\begin{tabular}{|c|c|c|c|c|}
\hline MSA & $\begin{array}{r}\text { Adoption } \\
\text { Rate } \\
\end{array}$ & $\begin{array}{r}\text { Standard } \\
\text { Error } \\
\end{array}$ & $\begin{array}{c}\text { Number of } \\
\text { Observations }\end{array}$ & $\begin{array}{l}\% \text { Establishments } \\
\text { in Top Quartile }\end{array}$ \\
\hline Rapid City, SD & $25.6 \%$ & $6.2 \%$ & 41 & $13.5 \%$ \\
\hline Missoula, MT & $19.1 \%$ & $6.1 \%$ & 32 & $17.6 \%$ \\
\hline Charlottesville, VA & $18.2 \%$ & $5.5 \%$ & 47 & $25.2 \%$ \\
\hline Decatur, IL & $17.3 \%$ & $5.9 \%$ & 37 & $16.5 \%$ \\
\hline Cheyenne, WY & $17.1 \%$ & $7.1 \%$ & 19 & $14.3 \%$ \\
\hline Dover, DE & $17.0 \%$ & $5.3 \%$ & 29 & $20.3 \%$ \\
\hline Jackson, TN & $16.9 \%$ & $4.9 \%$ & 55 & $3.7 \%$ \\
\hline Sioux Falls, SD & $16.8 \%$ & $3.9 \%$ & 86 & $24.6 \%$ \\
\hline Jackson, MI & $16.1 \%$ & $4.9 \%$ & 50 & $8.9 \%$ \\
\hline Casper, WY & $16.0 \%$ & $6.9 \%$ & 23 & $14.3 \%$ \\
\hline Average of Top Ten Small MSAs & $18.0 \%$ & & & $16.4 \%$ \\
\hline Average of Bottom Ten Small MSAs & $2.1 \%$ & & & $11.1 \%$ \\
\hline
\end{tabular}


Table 8a: Participation in Rural Areas by State

\begin{tabular}{|c|c|c|c|c|c|c|c|}
\hline Rank & State & Rural Rate & Std Error & Observations & Urban Rate & Std Error & Observations \\
\hline 1 & IN & $92.9 \%$ & $0.8 \%$ & 653 & $88.9 \%$ & $0.6 \%$ & 1745 \\
\hline 2 & MN & $92.9 \%$ & $0.7 \%$ & 566 & $91.0 \%$ & $0.5 \%$ & 1628 \\
\hline 3 & WI & $91.9 \%$ & $0.7 \%$ & 672 & $90.9 \%$ & $0.5 \%$ & 1728 \\
\hline 4 & WY & $91.6 \%$ & $1.7 \%$ & 96 & $82.1 \%$ & $2.8 \%$ & 42 \\
\hline 5 & $\mathrm{NY}$ & $91.5 \%$ & $0.8 \%$ & 365 & $89.4 \%$ & $0.4 \%$ & 4193 \\
\hline 6 & NE & $91.3 \%$ & $1.0 \%$ & 250 & $91.5 \%$ & $0.8 \%$ & 460 \\
\hline 7 & MI & $91.1 \%$ & $0.9 \%$ & 532 & $91.2 \%$ & $0.5 \%$ & 2623 \\
\hline 8 & $\mathrm{OH}$ & $90.9 \%$ & $0.8 \%$ & 735 & $89.5 \%$ & $0.4 \%$ & 3465 \\
\hline 9 & UT & $90.7 \%$ & $1.3 \%$ & 124 & $92.3 \%$ & $0.7 \%$ & 627 \\
\hline 10 & KS & $90.6 \%$ & $1.0 \%$ & 327 & $92.8 \%$ & $0.6 \%$ & 623 \\
\hline 11 & SD & $90.5 \%$ & $1.6 \%$ & 140 & $88.4 \%$ & $2.0 \%$ & 127 \\
\hline 12 & AR & $90.2 \%$ & $1.1 \%$ & 371 & $88.8 \%$ & $1.0 \%$ & 481 \\
\hline 13 & ID & $89.9 \%$ & $1.2 \%$ & 188 & $88.0 \%$ & $1.3 \%$ & 160 \\
\hline 14 & IA & $89.7 \%$ & $0.8 \%$ & 555 & $88.0 \%$ & $0.9 \%$ & 644 \\
\hline 15 & LA & $89.7 \%$ & $1.3 \%$ & 228 & $91.4 \%$ & $0.7 \%$ & 992 \\
\hline 16 & $\mathrm{MO}$ & $89.4 \%$ & $1.0 \%$ & 438 & $90.1 \%$ & $0.5 \%$ & 1505 \\
\hline 17 & WV & $89.3 \%$ & $1.2 \%$ & 223 & $89.3 \%$ & $1.3 \%$ & 242 \\
\hline 18 & IL & $89.1 \%$ & $1.0 \%$ & 585 & $89.2 \%$ & $0.4 \%$ & 3977 \\
\hline 19 & AL & $89.0 \%$ & $0.9 \%$ & 384 & $90.1 \%$ & $0.7 \%$ & 1138 \\
\hline 20 & VT & $89.0 \%$ & $1.2 \%$ & 107 & $78.9 \%$ & $2.0 \%$ & 71 \\
\hline 21 & KY & $88.7 \%$ & $0.8 \%$ & 574 & $89.4 \%$ & $0.7 \%$ & 798 \\
\hline 22 & WA & $88.7 \%$ & $1.2 \%$ & 215 & $92.1 \%$ & $0.5 \%$ & 1408 \\
\hline 23 & TX & $88.5 \%$ & $0.9 \%$ & 492 & $90.1 \%$ & $0.4 \%$ & 5073 \\
\hline 24 & AK & $88.4 \%$ & $1.6 \%$ & 97 & $90.1 \%$ & $2.1 \%$ & 91 \\
\hline 25 & $\mathrm{NC}$ & $88.1 \%$ & $0.8 \%$ & 895 & $89.9 \%$ & $0.5 \%$ & 2122 \\
\hline 26 & SC & $87.9 \%$ & $1.3 \%$ & 331 & $87.4 \%$ & $0.8 \%$ & 921 \\
\hline 27 & OK & $87.8 \%$ & $1.5 \%$ & 238 & $92.1 \%$ & $0.7 \%$ & 683 \\
\hline 28 & VA & $87.4 \%$ & $1.1 \%$ & 411 & $89.2 \%$ & $0.5 \%$ & 1603 \\
\hline 29 & MD & $87.2 \%$ & $2.2 \%$ & 114 & $87.8 \%$ & $0.8 \%$ & 1352 \\
\hline 30 & GA & $87.1 \%$ & $0.8 \%$ & 749 & $88.1 \%$ & $0.6 \%$ & 1859 \\
\hline 31 & $\mathrm{TN}$ & $87.1 \%$ & $1.2 \%$ & 545 & $90.3 \%$ & $0.6 \%$ & 1463 \\
\hline 32 & NV & $86.6 \%$ & $2.4 \%$ & 72 & $86.0 \%$ & $1.1 \%$ & 537 \\
\hline 33 & $\mathrm{NH}$ & $86.5 \%$ & $1.1 \%$ & 163 & $88.9 \%$ & $1.3 \%$ & 297 \\
\hline 34 & OR & $86.4 \%$ & $1.4 \%$ & 224 & $91.7 \%$ & $0.6 \%$ & 855 \\
\hline 35 & MS & $85.7 \%$ & $1.0 \%$ & 564 & $89.6 \%$ & $1.2 \%$ & 302 \\
\hline 36 & $\mathrm{CO}$ & $84.6 \%$ & $1.1 \%$ & 153 & $90.0 \%$ & $0.6 \%$ & 1246 \\
\hline 37 & PA & $84.6 \%$ & $1.0 \%$ & 502 & $89.6 \%$ & $0.4 \%$ & 3489 \\
\hline 38 & ND & $83.8 \%$ & $1.1 \%$ & 112 & $89.0 \%$ & $1.4 \%$ & 152 \\
\hline 39 & NM & $83.1 \%$ & $1.9 \%$ & 131 & $84.5 \%$ & $1.2 \%$ & 261 \\
\hline 40 & CA & $82.0 \%$ & $1.8 \%$ & 183 & $91.4 \%$ & $0.3 \%$ & 8379 \\
\hline \begin{tabular}{|l|}
41 \\
\end{tabular} & FL & $81.9 \%$ & $1.8 \%$ & 206 & $87.9 \%$ & $0.5 \%$ & 4289 \\
\hline 42 & MT & $81.9 \%$ & $2.1 \%$ & 114 & $72.2 \%$ & $2.2 \%$ & 90 \\
\hline 43 & ME & $81.8 \%$ & $1.2 \%$ & 202 & $92.1 \%$ & $1.5 \%$ & 217 \\
\hline 44 & $\mathrm{HI}$ & $81.2 \%$ & $1.8 \%$ & 100 & $92.4 \%$ & $1.1 \%$ & 231 \\
\hline 45 & $\mathrm{AZ}$ & $79.1 \%$ & $2.4 \%$ & 89 & $90.0 \%$ & $0.6 \%$ & 1300 \\
\hline 46 & CT & $78.9 \%$ & $1.2 \%$ & 89 & $89.7 \%$ & $0.6 \%$ & 1136 \\
\hline \begin{tabular}{|l|}
47 \\
\end{tabular} & MA & $74.0 \%$ & $3.5 \%$ & 33 & $92.6 \%$ & $0.5 \%$ & 2221 \\
\hline 8 & $\mathrm{DE}$ & $71.5 \%$ & $4.6 \%$ & 31 & $85.5 \%$ & $1.4 \%$ & 208 \\
\hline 49 & RI & $67.9 \%$ & $2.6 \%$ & 21 & $92.4 \%$ & $1.1 \%$ & 290 \\
\hline
\end{tabular}


Table 8b: Enhancement in Rural Areas by State

\begin{tabular}{|c|c|c|c|c|c|c|c|}
\hline Rank & State & Rural Rate & Std Error & Observations & Urbana Rate & Std Error & Observations \\
\hline 1 & MN & $15.5 \%$ & $1.6 \%$ & 566 & $15.5 \%$ & $0.9 \%$ & 1628 \\
\hline 2 & RI & $14.9 \%$ & $6.4 \%$ & 21 & $15.5 \%$ & $2.2 \%$ & 290 \\
\hline 3 & $\mathrm{SC}$ & $14.9 \%$ & $1.7 \%$ & 331 & $10.7 \%$ & $1.1 \%$ & 921 \\
\hline 4 & LA & $13.4 \%$ & $2.3 \%$ & 228 & $12.0 \%$ & $1.2 \%$ & 992 \\
\hline 5 & $\mathrm{NY}$ & $13.0 \%$ & $1.8 \%$ & 365 & $12.7 \%$ & $0.6 \%$ & 4193 \\
\hline 6 & $\mathrm{OH}$ & $12.5 \%$ & $1.2 \%$ & 735 & $12.4 \%$ & $0.6 \%$ & 3465 \\
\hline 7 & WV & $12.5 \%$ & $2.0 \%$ & 223 & $8.6 \%$ & $1.5 \%$ & 242 \\
\hline 8 & WY & $12.5 \%$ & $3.4 \%$ & 96 & $18.5 \%$ & $5.7 \%$ & 42 \\
\hline 9 & UT & $12.4 \%$ & $3.0 \%$ & 124 & $16.2 \%$ & $1.6 \%$ & 627 \\
\hline 10 & $\mathrm{AK}$ & $12.2 \%$ & $3.2 \%$ & 97 & $15.2 \%$ & $3.8 \%$ & 91 \\
\hline 11 & $\mathrm{DE}$ & $12.2 \%$ & $5.1 \%$ & 31 & $14.2 \%$ & $2.2 \%$ & 208 \\
\hline 12 & $\mathrm{NV}$ & $12.1 \%$ & $3.8 \%$ & 72 & $9.4 \%$ & $1.3 \%$ & 537 \\
\hline 13 & ND & $11.8 \%$ & $3.0 \%$ & 112 & $8.7 \%$ & $2.2 \%$ & 152 \\
\hline 14 & CT & $11.7 \%$ & $2.3 \%$ & 89 & $14.6 \%$ & $1.1 \%$ & 1136 \\
\hline 15 & WA & $11.6 \%$ & $2.2 \%$ & 215 & $13.5 \%$ & $1.0 \%$ & 1408 \\
\hline 16 & WI & $11.6 \%$ & $1.4 \%$ & 672 & $13.4 \%$ & $0.9 \%$ & 1728 \\
\hline 17 & IA & $11.4 \%$ & $1.4 \%$ & 555 & $15.5 \%$ & $1.4 \%$ & 644 \\
\hline 18 & ID & $11.4 \%$ & $2.4 \%$ & 188 & $10.2 \%$ & $2.5 \%$ & 160 \\
\hline 19 & IL & $11.4 \%$ & $1.2 \%$ & 585 & $14.3 \%$ & $0.6 \%$ & 3977 \\
\hline 20 & IN & $11.4 \%$ & $1.3 \%$ & 653 & $12.2 \%$ & $0.8 \%$ & 1745 \\
\hline 21 & AL & $10.9 \%$ & $1.6 \%$ & 384 & $11.9 \%$ & $1.0 \%$ & 1138 \\
\hline 22 & GA & $10.8 \%$ & $1.2 \%$ & 749 & $14.0 \%$ & $0.9 \%$ & 1859 \\
\hline 23 & VA & $10.3 \%$ & $1.6 \%$ & 411 & $13.8 \%$ & $0.8 \%$ & 1603 \\
\hline 24 & VT & $10.2 \%$ & $2.9 \%$ & 107 & $11.3 \%$ & $3.7 \%$ & 71 \\
\hline 25 & OR & $10.1 \%$ & $2.0 \%$ & 224 & $14.6 \%$ & $1.2 \%$ & 855 \\
\hline 26 & AR & $9.9 \%$ & $1.6 \%$ & 371 & $13.8 \%$ & $1.6 \%$ & 481 \\
\hline 27 & $\mathrm{HI}$ & $9.6 \%$ & $3.0 \%$ & 100 & $10.1 \%$ & $2.1 \%$ & 231 \\
\hline 28 & KY & $9.6 \%$ & $1.3 \%$ & 574 & $13.0 \%$ & $1.1 \%$ & 798 \\
\hline 29 & MO & $9.6 \%$ & $1.5 \%$ & 438 & $13.6 \%$ & $0.8 \%$ & 1505 \\
\hline 30 & MS & $9.6 \%$ & $1.3 \%$ & 564 & $13.4 \%$ & $2.0 \%$ & 302 \\
\hline 31 & MT & $9.4 \%$ & $2.7 \%$ & 114 & $15.3 \%$ & $3.5 \%$ & 90 \\
\hline 32 & $\mathrm{TN}$ & $9.3 \%$ & $1.3 \%$ & 545 & $12.2 \%$ & $0.9 \%$ & 1463 \\
\hline 33 & TX & $9.3 \%$ & $1.4 \%$ & 492 & $14.6 \%$ & $0.6 \%$ & 5073 \\
\hline 34 & OK & $9.2 \%$ & $1.9 \%$ & 238 & $15.0 \%$ & $1.4 \%$ & 683 \\
\hline 35 & $\mathrm{AZ}$ & $9.1 \%$ & $2.9 \%$ & 89 & $11.5 \%$ & $0.9 \%$ & 1300 \\
\hline 36 & $\mathrm{CA}$ & $9.1 \%$ & $1.8 \%$ & 183 & $13.8 \%$ & $0.5 \%$ & 8379 \\
\hline 37 & $\mathrm{CO}$ & $9.1 \%$ & $3.0 \%$ & 153 & $16.9 \%$ & $1.1 \%$ & 1246 \\
\hline 38 & $\mathrm{NC}$ & $8.9 \%$ & $1.0 \%$ & 895 & $12.3 \%$ & $0.8 \%$ & 2122 \\
\hline 39 & KS & $8.2 \%$ & $1.5 \%$ & 327 & $13.1 \%$ & $1.2 \%$ & 623 \\
\hline 40 & PA & $8.2 \%$ & $1.3 \%$ & 502 & $12.9 \%$ & $0.6 \%$ & 3489 \\
\hline 41 & NE & $7.7 \%$ & $1.7 \%$ & 250 & $15.2 \%$ & $1.7 \%$ & 460 \\
\hline 42 & $\mathrm{NH}$ & $7.7 \%$ & $2.3 \%$ & 163 & $11.0 \%$ & $1.9 \%$ & 297 \\
\hline 43 & SD & $6.9 \%$ & $2.3 \%$ & 140 & $20.9 \%$ & $3.6 \%$ & 127 \\
\hline 44 & $\mathrm{FL}$ & $6.8 \%$ & $1.9 \%$ & 206 & $12.8 \%$ & $0.6 \%$ & 4289 \\
\hline 45 & NM & $6.4 \%$ & $2.2 \%$ & 131 & $13.4 \%$ & $2.1 \%$ & 261 \\
\hline 46 & MA & $5.6 \%$ & $3.6 \%$ & 33 & $14.4 \%$ & $0.9 \%$ & 2221 \\
\hline 47 & MD & $5.6 \%$ & $3.0 \%$ & 114 & $15.5 \%$ & $1.0 \%$ & 1352 \\
\hline 48 & ME & $5.6 \%$ & $1.9 \%$ & 202 & $11.0 \%$ & $2.3 \%$ & 217 \\
\hline 49 & MI & $5.6 \%$ & $1.4 \%$ & \begin{tabular}{l|l|}
532 \\
\end{tabular} & $13.7 \%$ & $0.8 \%$ & 2623 \\
\hline
\end{tabular}


Table 9a: Participation Among States

\begin{tabular}{|c|c|c|c|c|}
\hline Rank & State & $\begin{array}{r}\text { Adoption } \\
\text { Rate }\end{array}$ & $\begin{array}{r}\text { Standard } \\
\text { Error }\end{array}$ & $\begin{array}{r}\text { Number of } \\
\text { Observations }\end{array}$ \\
\hline 1 & MA & $92.4 \%$ & $0.4 \%$ & 2254 \\
\hline 2 & KS & $92.0 \%$ & $0.5 \%$ & 950 \\
\hline 3 & WA & $91.9 \%$ & $0.5 \%$ & 1624 \\
\hline 4 & $\overline{\mathrm{UT}}$ & $91.8 \%$ & $0.6 \%$ & 751 \\
\hline 5 & CA & $91.4 \%$ & $0.3 \%$ & 8581 \\
\hline 6 & $\mathrm{MN}$ & $91.3 \%$ & $0.4 \%$ & 2194 \\
\hline 7 & OK & $91.3 \%$ & $0.7 \%$ & 921 \\
\hline 8 & $\mathrm{NE}$ & $91.3 \%$ & $0.7 \%$ & 710 \\
\hline 9 & MI & $91.2 \%$ & $0.4 \%$ & 3159 \\
\hline 10 & LA & $91.2 \%$ & $0.6 \%$ & 1220 \\
\hline 11 & WI & $91.0 \%$ & $0.4 \%$ & 2400 \\
\hline 12 & OR & $90.6 \%$ & $0.5 \%$ & 1079 \\
\hline 13 & IN & $90.6 \%$ & $0.5 \%$ & 2398 \\
\hline 14 & WY & $90.6 \%$ & $1.5 \%$ & 138 \\
\hline 15 & SD & $90.5 \%$ & $1.3 \%$ & 267 \\
\hline 16 & RI & $90.5 \%$ & $1.0 \%$ & 311 \\
\hline 17 & TX & $90.0 \%$ & $0.3 \%$ & 5572 \\
\hline 18 & $\mathrm{MO}$ & $89.8 \%$ & $0.5 \%$ & 1943 \\
\hline 19 & NJ & $89.8 \%$ & $0.5 \%$ & 2020 \\
\hline 20 & TN & $89.8 \%$ & $0.6 \%$ & 2008 \\
\hline 21 & $\mathrm{AL}$ & $89.8 \%$ & $0.6 \%$ & 1522 \\
\hline 22 & $\mathrm{OH}$ & $89.7 \%$ & $0.4 \%$ & 4203 \\
\hline 23 & $\mathrm{CO}$ & $89.6 \%$ & $0.6 \%$ & 1403 \\
\hline 24 & NY & $89.5 \%$ & $0.3 \%$ & 4558 \\
\hline 25 & $\mathrm{NC}$ & $89.4 \%$ & $0.4 \%$ & 3021 \\
\hline 26 & $\mathrm{AK}$ & $89.4 \%$ & $1.4 \%$ & 188 \\
\hline 27 & $\mathrm{AZ}$ & $89.4 \%$ & $0.6 \%$ & 1389 \\
\hline 28 & $\mathrm{WV}$ & $89.3 \%$ & $0.9 \%$ & 465 \\
\hline 29 & $\mathrm{HI}$ & $89.3 \%$ & $0.9 \%$ & 331 \\
\hline 30 & PA & $89.2 \%$ & $0.4 \%$ & 4000 \\
\hline 31 & IL & $89.1 \%$ & $0.4 \%$ & 4563 \\
\hline 32 & AR & $89.1 \%$ & $0.7 \%$ & 853 \\
\hline 33 & ID & $89.1 \%$ & $0.9 \%$ & 348 \\
\hline 34 & CT & $89.0 \%$ & $0.6 \%$ & 1199 \\
\hline 35 & VA & $89.0 \%$ & $0.5 \%$ & 2015 \\
\hline 36 & KY & $88.9 \%$ & $0.6 \%$ & 1372 \\
\hline 37 & ND & $88.8 \%$ & $0.9 \%$ & 268 \\
\hline 38 & IA & $88.6 \%$ & $0.6 \%$ & 1200 \\
\hline 39 & $\mathrm{NH}$ & $88.3 \%$ & $1.0 \%$ & 460 \\
\hline 40 & MD & $88.2 \%$ & $0.5 \%$ & 1466 \\
\hline 41 & FL & $87.7 \%$ & $0.5 \%$ & 4501 \\
\hline 42 & GA & $87.7 \%$ & $0.5 \%$ & 2610 \\
\hline 43 & $\mathrm{SC}$ & $87.7 \%$ & $0.7 \%$ & 1252 \\
\hline 44 & ME & $87.5 \%$ & $0.9 \%$ & 419 \\
\hline 45 & MS & $87.3 \%$ & $0.8 \%$ & 866 \\
\hline 46 & VT & $86.6 \%$ & $1.0 \%$ & 178 \\
\hline 47 & NV & $86.5 \%$ & $1.0 \%$ & 609 \\
\hline 48 & DC & $85.9 \%$ & $0.5 \%$ & 285 \\
\hline 49 & NM & $84.1 \%$ & $1.0 \%$ & 392 \\
\hline 50 & $\mathrm{DE}$ & $84.0 \%$ & $1.3 \%$ & 239 \\
\hline 51 & MT & $81.3 \%$ & $1.5 \%$ & 204 \\
\hline
\end{tabular}


Table 9b: Enhancement Among States

\begin{tabular}{|c|c|c|c|c|}
\hline Rank & State & $\begin{array}{r}\text { Adoption } \\
\text { Rate }\end{array}$ & $\begin{array}{r}\text { Standard } \\
\text { Error }\end{array}$ & $\begin{array}{r}\text { Number of } \\
\text { Observations }\end{array}$ \\
\hline 1 & $\mathrm{CO}$ & $16.7 \%$ & $1.0 \%$ & 1403 \\
\hline 2 & UT & $15.6 \%$ & $1.4 \%$ & 751 \\
\hline 3 & $\mathrm{MN}$ & $15.5 \%$ & $0.8 \%$ & 2194 \\
\hline 4 & RI & $15.3 \%$ & $2.1 \%$ & 311 \\
\hline 5 & WY & $15.1 \%$ & $3.0 \%$ & 138 \\
\hline 6 & $\mathrm{CT}$ & $14.5 \%$ & $1.1 \%$ & 1199 \\
\hline 7 & MA & $14.3 \%$ & $0.9 \%$ & 2254 \\
\hline 8 & SD & $14.2 \%$ & $2.1 \%$ & 267 \\
\hline 9 & TX & $14.2 \%$ & $0.5 \%$ & 5572 \\
\hline 10 & $\mathrm{DE}$ & $14.2 \%$ & $2.1 \%$ & 239 \\
\hline 11 & DC & $13.8 \%$ & $0.9 \%$ & 285 \\
\hline 12 & AK & $13.8 \%$ & $2.5 \%$ & 188 \\
\hline 13 & OR & $13.8 \%$ & $1.1 \%$ & 1079 \\
\hline 14 & IA & $13.8 \%$ & $1.0 \%$ & 1200 \\
\hline 15 & NJ & $13.8 \%$ & $0.8 \%$ & 2020 \\
\hline 16 & $\mathrm{OK}$ & $13.7 \%$ & $1.2 \%$ & 921 \\
\hline 17 & IL & $13.7 \%$ & $0.6 \%$ & 4563 \\
\hline 18 & $\mathrm{CA}$ & $13.7 \%$ & $0.5 \%$ & 8581 \\
\hline 19 & WA & $13.3 \%$ & $0.9 \%$ & 1624 \\
\hline 20 & VA & $13.3 \%$ & $0.7 \%$ & 2015 \\
\hline 21 & MI & $13.3 \%$ & $0.7 \%$ & 3159 \\
\hline 22 & GA & $13.3 \%$ & $0.7 \%$ & 2610 \\
\hline 23 & WI & $13.3 \%$ & $0.7 \%$ & 2400 \\
\hline 24 & MD & $13.0 \%$ & $0.8 \%$ & 1466 \\
\hline 25 & MT & $12.9 \%$ & $2.3 \%$ & 204 \\
\hline 26 & NE & $12.8 \%$ & $1.3 \%$ & 710 \\
\hline 27 & MO & $12.8 \%$ & $0.7 \%$ & 1943 \\
\hline 28 & NY & $12.7 \%$ & $0.6 \%$ & 4558 \\
\hline 29 & $\mathrm{OH}$ & $12.5 \%$ & $0.6 \%$ & 4203 \\
\hline 30 & FL & $12.5 \%$ & $0.6 \%$ & 4501 \\
\hline 31 & PA & $12.4 \%$ & $0.6 \%$ & 4000 \\
\hline 32 & LA & $12.2 \%$ & $1.0 \%$ & 1220 \\
\hline 33 & IN & $12.1 \%$ & $0.7 \%$ & 2398 \\
\hline 34 & $\mathrm{AR}$ & $12.0 \%$ & $1.2 \%$ & 853 \\
\hline 35 & KY & $11.7 \%$ & $0.8 \%$ & 1372 \\
\hline 36 & $\mathrm{AL}$ & $11.7 \%$ & $0.9 \%$ & 1522 \\
\hline 37 & $\mathrm{KS}$ & $11.6 \%$ & $1.0 \%$ & 950 \\
\hline 38 & TN & $11.6 \%$ & $0.8 \%$ & 2008 \\
\hline 39 & NM & $11.6 \%$ & $1.7 \%$ & 392 \\
\hline 40 & $\mathrm{NC}$ & $11.5 \%$ & $0.6 \%$ & 3021 \\
\hline 41 & $\mathrm{AZ}$ & $11.3 \%$ & $0.9 \%$ & 1389 \\
\hline 42 & MS & $11.2 \%$ & $1.1 \%$ & 866 \\
\hline 43 & VT & $11.0 \%$ & $2.3 \%$ & 178 \\
\hline 44 & ID & $10.9 \%$ & $1.7 \%$ & 348 \\
\hline 45 & $\mathrm{NH}$ & $10.6 \%$ & $1.5 \%$ & 460 \\
\hline 46 & SC & $10.5 \%$ & $0.9 \%$ & 1252 \\
\hline 47 & ND & $10.3 \%$ & $1.8 \%$ & 268 \\
\hline 48 & $\mathrm{HI}$ & $10.0 \%$ & $1.7 \%$ & 331 \\
\hline 49 & ME & $9.9 \%$ & $1.5 \%$ & 419 \\
\hline 50 & NV & $9.8 \%$ & $1.2 \%$ & 609 \\
\hline 51 & WV & $8.8 \%$ & $1.3 \%$ & 465 \\
\hline
\end{tabular}




\section{A.1. Data Appendix}

Our analysis sample was constructed to address three general types of measurement error: nonresponse bias, timing bias, and sampling bias. Non-response bias occurs when survey respondents do not answer all questions they are asked. This occurs because HH makes the CI database publicly available, and establishments may not want to reveal all of their strategic IT investments. In addition, HH used two types of surveys on IT usage, one short and one long. Because we apply a uniform standard when identifying Internet usage, this creates a kind on non-response bias. HH survey methodology may also create timing bias. HH uses teams of interviewers to survey establishments throughout the calendar year. Because this technology may still be diffusing over our sample, establishments surveyed earlier will be less likely to participate or enhance than an otherwise identical establishment that is surveyed later. Last, the sample of establishments in the CI database may not be representative. Because HH collected the CI database as a marketing tool, it may over-sample industries or locations that are particularly interesting to its customers.

Each problem requires correction, though none has more than a limited impact on our sample. A combination of econometric estimation and weighting mitigates the effects of these biases.

\section{A.2. How large a bias, if any?}

We first looked for non-response bias. An establishment will not report any use of IT for one of three possible reasons. First, the establishment may refuse to answer questions on IT usage. Second, HH may not have surveyed the establishment on IT (though it may have surveyed the establishment about other aspects of the organization). Third, the establishment may in fact have no IT investments.

Accordingly, we dropped establishments who left too many incomplete answers. This accounted for approximately 13,000 of the dropped establishments. We also excluded a small number of observations for which there was obvious coding error. ${ }^{35}$ After these observations were dropped, there remained 664 observations that still reported no IT investment. Many were small firms in industries that are not traditionally technologically intensive. ${ }^{36}$ We retained these establishments because dropping them would have created too optimistic a picture in the sample. ${ }^{37}$

\footnotetext{
${ }^{35}$ There were less than 20 such observations.

${ }^{36}$ For example, Route 66 Bingo of Albuquerque, NM and Lake Shore Little League of Athol Springs, NY had no IT investments. These are quite plausible results, and should be included.

${ }^{37}$ This does not fully eliminate non-response bias, but we checked for it where we had outside information. We discovered a mild non-response bias among retail establishments, particularly for participation. This may reflect strategic non-reporting by firms (Wal-Mart in particular) who consider information technology a key strategy. Thus, our estimates should be viewed as conservative in retailing.
} 
We now discuss timing bias. Establishments in our sample were surveyed between July 1998 and August 2000. Since participation and enhancement technologies diffused between 1998 and 2000, earlier respondents are likely to have a lower likelihood of adopting. We correct for this in our econometrics below.

In addition, HH changed survey methodology during our sample period. HH introduced more IT questions to the short survey in June 1999; prior to then only the long survey contained IT questions. As a result, we dropped any establishments surveyed before June 1999 that received the shorter survey. This accounted for over sixteen thousand observations dropped. Consequently, in our final sample most establishments were surveyed between June 1999 and December 2000, after the change in sampling methodology. Only $11.5 \%$ of all respondents were surveyed prior to June 1999.

This leaves a subtle bias that still needs correction. HH surveyed 38.7 percent of remaining establishments with the short form. Since these establishments provided less information to HH on Internet usage, it will be mildly more difficult to identify their adoption of participatory or business process enhancing technologies. ${ }^{38}$ The fraction of respondents responding to the short survey, and the potential response bias, also varies over time. We address this bias in our econometrics.

\section{A.3.Econometric procedure}

To be precise, we assume that the value to an establishment $j$ of participating in the Internet is

$$
y_{j}=\sum_{i} \alpha_{i} d_{i j}+\sum_{l} \beta_{l} d_{l j}+\sum_{t} \gamma_{t} d_{t j}+\sum_{t>19905} \delta_{t} d_{t j} d_{p j}+\varepsilon_{j}
$$

where $d_{i j}$ and $d_{l j}$ are dummy variables indicating the industry and location of the establishment, $d_{t j}$ indicates the month in which the establishment was surveyed, and $d_{p j}$ indicates whether the establishment responded to the long survey. ${ }^{39}$ The variable $y_{j}$ is latent, we observe only whether or not the establishment adopts participation. If we assume the error term $\varepsilon_{j}$ is i.i.d. normal, then the probability that establishment $j$ adopts will be a probit,

$$
P_{j}=\Phi\left[\sum_{i} \alpha_{i} d_{i j}+\sum_{l} \beta_{l} d_{l j}+\sum_{t} \gamma_{t} d_{t j}+\sum_{t>19905} \delta_{t} d_{t j} d_{p j}\right]
$$

where $\Phi[\square]$ represents the univariate normal cumulative distribution function. The probability of adopting enhancement to business processes can be written similarly. We then use the parameter

\footnotetext{
${ }^{38}$ In the establishments where both forms of data were collected, we checked for similar responses to different questions. Hence, our methods will align results in spite of source of data.

${ }^{39} \mathrm{We}$ interact the long survey dummy with time. If establishments are selected for the long survey endogenously by HH, then this suggests the impact of receiving the long survey on adoption may vary over time.
} 
estimates of the probit to estimate the predicted probability that an establishment will adopt as if the survey date occurred in the latter half of 2000 and the establishment has responded to the long survey. We next adjusted the predicted results by the sample weights, adjusted for establishment definition. The resulting numbers are the average adoption rate in a location or an industry in the second half of 2000. These estimates equal data when every establishment is surveyed in the latter part of 2000.

\section{A.4 Definitions}

The CI database includes several measures of establishment Internet usage. From these we constructed measures of participation and enhancement. Identifying participation was simple, while identifying enhancement was comparatively more difficult.

We desire a definition of participation that involves using Internet technologies to lower communications costs while maintaining existing production, sales, and distribution techniques. It should be unrelated to whether an establishment has a presence on the World Wide Web, or makes available products and services to consumers on the web. Moreover, participatory investment assumes nothing about intensity. Establishments that participate in the Internet are not necessarily "light" users. ${ }^{40}$

To be counted as participating in the Internet, an establishment must engage in two or more of the following activities: (1) have an Internet service provider; (2) indicate it has basic access; (3) use commerce, customer service, education, extranet, homepage, publications, purchasing or technical support; (4) use the Internet for usage, or has an intranet or email based on TCP/IP protocols; (5) indicate there are Internet users or Internet developers on site; or (6) outsource some Internet activities. We looked for two or more activities to guard against "false positives". As it was, this was a minor issue. Most respondents responded affirmatively to many of these criteria.

We construct a definition for enhancement. Business process enhancement is the type of investment commonly described in books on electronic commerce. ${ }^{41}$ Typically this involves altering sales, manufacturing, production, or distribution systems within the firm. We aggregate many applications under this umbrella. Business-to-business or business-to-consumer e-commerce fall in this category, so too does TCP/IP versions of software such as enterprise resource planning or customer relationship management. Again, enhancement assumes nothing about the intensity of use, nor about complexity. ${ }^{42}$ Most establishments that do enhancement are intensive users. They also may face

\footnotetext{
${ }^{40}$ Thus, our study is distinct from those that examine the difference between adoption and usage in IT (e.g., Fichman and Kemerer 1997, 1999).

${ }^{41}$ See e.g., Kalakota and Whinston (1996), Kalakota and Robinson (1999), Choi and Whinston (2000).

${ }^{42}$ While participation can involve straightforward application of new technologies, business process transformation requires disruption to the existing sales, distribution, and production techniques. For example, adoption of e-commerce often involves
} 
considerable co-invention costs to effectively integrate these investments with legacy investments and processes. Still, we expect there is much heterogeneity in intensity and complexity of use among adopters of enhancement, given any definition we employ. We hope to explore this further in future work.

To be defined as performing enhancement, an establishment must first surpass a threshold for participatory investment. We initially tried a definition that was isomorphic to participation, with a more demanding threshold. That is, an establishment is counted as enhancing business processes when two or more hold: (1) the establishment uses two or more languages commonly used for web applications, such as Active-X, Java, CGI, Perl, VB Script, or XML; (2) the establishment has over five Internet developers; (3) the establishment has two or more "e-business" applications such as customer service, education, extranet, publications, purchasing, or technical support; (4) the establishment reports LAN software that performs one of several functions: e-commerce, enterprise resource planning, web development, or web server; (5) the establishment has an Internet server that is a UNIX workstation or server, mainframe, or minicomputer, or has 5 or more PC servers, or has Internet storage greater than 20 gigabytes; (6) the establishment answers three or more questions related to Internet server software, Internet/web software, or intranet applications.

We tested this definition and found that it generated many false positives. These false positives arose more frequently when an establishment was experimenting with, but not actually regularly using, Internet business processes. In other words, they were trying something small or contracting out for a test. To correct for this, we exclude establishments in one of three cases: 1 . They indicate they have outsourced hosting of their Internet/web servers; 2 . These experimenters responded affirmatively to exactly two of (1) through (6) but not any question about commerce; or 3. They have commerce but respond affirmatively to less than two of (1) through (6). Such establishments typically had not yet done very much (but might someday). We show the results of this difference in Table 3.

Our definition is mildly sensitive to the survey used by HH for an establishment, so we correct for this. ${ }^{43}$ In our estimated predictions, we normalize on results as if all establishments responded to the long survey.

the creation of an entirely new distribution channel; a distribution channel that requires considerable organizational change in firm sales and distribution techniques.

${ }^{43}$ The long survey is particularly useful in identifying business process establishments, and is the only source of information on business process criteria (5) and (6) and is also the only source of information on outsourcing. Because we apply a consistent definition of adoption across all establishments, there exists a natural bias in that long survey establishments will be more likely adopters. Some of these might reflect our definition and some of it certainly reflects HH's tendency to survey big adopters with the long form. 